Florida International University

FIU Digital Commons

6-19-2020

\title{
The Effects of Continuous Video Prompting on Teaching Daily Living Skills to Individuals with Autism Spectrum Disorder
}

Enas Altaf

FIU, eltaf001@fiu.edu

Follow this and additional works at: https://digitalcommons.fiu.edu/etd

Part of the Special Education and Teaching Commons

\section{Recommended Citation}

Altaf, Enas, "The Effects of Continuous Video Prompting on Teaching Daily Living Skills to Individuals with Autism Spectrum Disorder" (2020). FIU Electronic Theses and Dissertations. 4503.

https://digitalcommons.fiu.edu/etd/4503

This work is brought to you for free and open access by the University Graduate School at FIU Digital Commons. It has been accepted for inclusion in FIU Electronic Theses and Dissertations by an authorized administrator of FIU Digital Commons. For more information, please contact dcc@fiu.edu. 


\section{FLORIDA INTERNATIONAL UNIVERSITY}

Miami, Florida

\section{THE EFFECTS OF CONTINUOUS VIDEO PROMPTING ON TEACHING DAILY LIVING SKILLS TO INDIVIDUALS WITH AUTISM SPECTRUM DISORDER}

A dissertation submitted in partial fulfillment of

the requirements for the degree of

\section{DOCTOR OF EDUCATION}

in

EXCEPTIONAL STUDENT EDUCATION

by

Enas MohammedNour Altaf

2020 
To: Dean Michael R. Heithaus

College of Arts, Sciences and Education

This dissertation, written by Enas MohammedNour Altaf and entitled The Effects of Continuous Video Prompting on Teaching Daily Living Skills to Individuals with Autism Spectrum Disorder, having been approved in respect to style and intellectual content, is referred to you for judgment.

We have read this dissertation and recommend that it be approved.

$\begin{array}{r}\hline \text { Elizabeth Cramer } \\ \hline \text { Liana Gonzalez } \\ \hline \text { Kyle D. Bennett, Major Professor }\end{array}$

Date of Defense: June 19, 2020

The dissertation of Enas MohammedNour Altaf is approved.

Dean Michael R. Heithaus College of Arts, Sciences and Education

Andrés G. Gil

Vice President for Research and Economic Development and Dean of the University Graduate School

Florida International University, 2020 
(C) Copyright 2020 by Enas MohammedNour Altaf All rights reserved. 


\section{DEDICATION}

The road travelled on my journey to earn a Doctor of Education has been difficult. Luckily for me, I have had great support on this journey from many people in my life. When I look back at all the support I have received, it becomes apparent that this journey would not have been as successful without the love, encouragement, and countless support of my parents, especially from my father. I dedicate this dissertation to my parents. I could not have come this far without their support and unconditional love. Dad, I would like to take this moment to say thank you. Thank you for teaching me the value of education. Thank you for teaching me that I can do anything I set my mind to. Thank you for believing in me even during the times I did not believe in myself. Thank you for all the motivation that you gave to me through this whole journey. Mom, I would like to thank you for all the sacrificing of your time, prayers, and inspiration that you have given me through this life. 


\section{ACKNOWLEDGMENTS}

First and foremost, I would like to thank my major professor, Dr. Kyle D. Bennett for his advice, patience, and support. Without his assistance and vast support, this dissertation would not have been possible. It was a joy, pleasure, and privilege working with him.

I would like to thank all my committee members, Dr. Elizabeth Cramer, Dr. Liana Gonzalez, and Dr. Haiying Long for their invaluable feedback and support.

I would also like to take a moment here to express appreciation and love for my brothers and sister, and also my friend, Mosa. Their encouragement through this process made the road, not easy, but rather more bearable.

I would like to express my appreciation to my friend Dr. Judy Salmon for her support, listening to me, and standing beside me through the whole journey towards a doctoral degree. I would also like to thank one of my professors at Adelphi University, Dr. Anne Mungai for her continuous support on this journey. I would like to express my gratitude to my neighbors in New York for their support since I have known them.

As a student studying abroad, I was far from home. There were many times I experienced homesickness, and at times, I wanted to give up. Yet, through my faith in God, I was able to persevere and feel less homesick. God gave me strength and peace through my time away from home; thanks to God. 


\begin{abstract}
OF THE DISSERTATION
THE EFFECTS OF CONTINUOUS VIDEO PROMPTING ON TEACHING DAILY

LIVING SKILLS TO INDIVIDUALS WITH AUTISM SPECTRUM DISORDER
\end{abstract}

by

Enas MohammedNour Altaf

Florida International University, 2020

Miami Florida

\title{
Professor Kyle D. Bennett, Major Professor
}

Over the past decade, there has been a trend of the growing prevalence of autism spectrum disorder (ASD) diagnoses. Autism spectrum disorder is a neurodevelopmental disorder that affects behavior, learning, and communication. Many with ASD emit problem behaviors that create challenges for learning in many areas of life, including the acquisition of daily living skills (DLS).

There have been numerous interventions developed to teach individuals with ASD; some interventions are aimed at reducing problem behaviors while others teach different skills, including DLS. Over the past ten years, video-based instruction (VBI) has proven useful to teach individuals with ASD. There are several approaches to VBI, and a recent variant includes continuous video prompting (CVP).

With CVP, the video plays in a repeating loop for each task step until the learner completes the task. The current study sought to determine the effectiveness of CVP on teaching a DLS to four middle school children with ASD. The purpose of the study was to examine the effectiveness of using CVP in isolation while recording the number of 
video loops needed to evoke correct behavior. The DLS taught to the children was collating three different colors of paper, placing the papers in an envelope, sealing the envelope, and placing the envelope in a basket. The study's design was a multiple probe across participants. A baseline was applied for each participant before the introduction of the intervention, which was followed by maintenance sessions. The results of the study demonstrated that all participants improved in their performance of the selected task during the CVP intervention, with two participants maintaining higher levels of performing the task within 2 minutes when comparing baseline to maintenance sessions. The other two participants did not maintain the task when considering the 2-minute time limit. One participant reduced to near baseline levels, and the other one had variable responding. However, one of these participants did maintain the skill when not considering the 2-minute time limit. These results are promising for teaching children with ASD, but further research is needed to determine the effectiveness of CVP for teaching DLS to children with ASD. 


\section{TABLE OF CONTENTS}

CHAPTER

PAGE

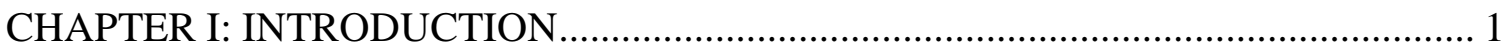

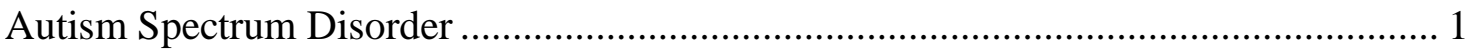

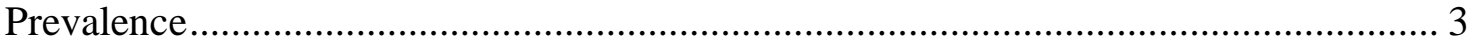

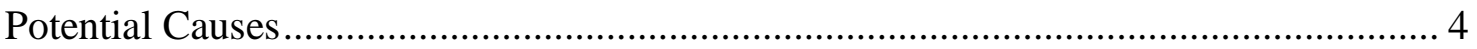

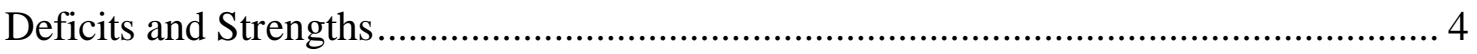

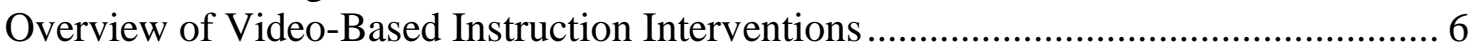

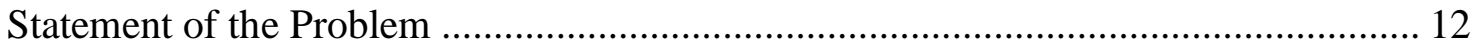

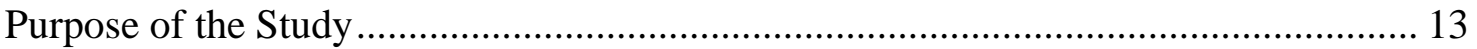

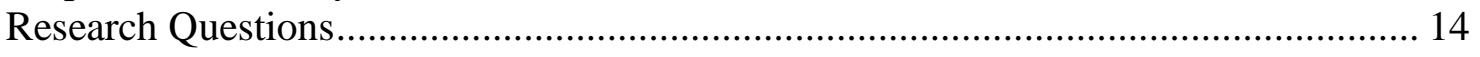

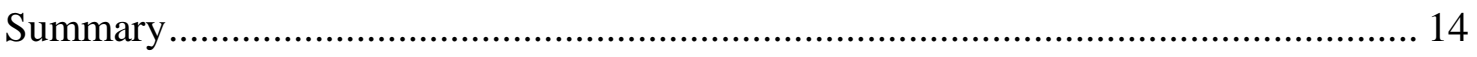

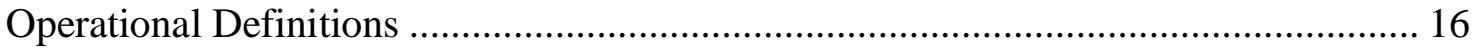

CHAPTER II: LITERATURE REVIEW ……………........................................ 18

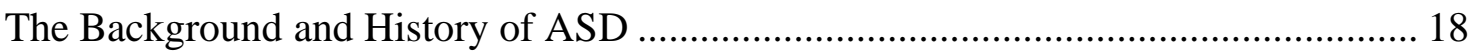

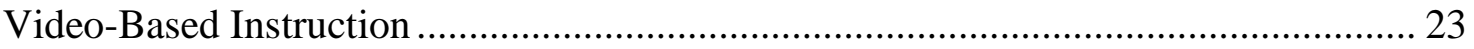

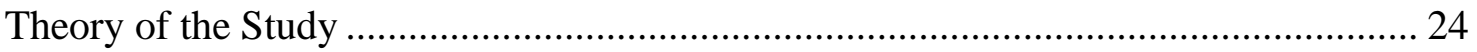

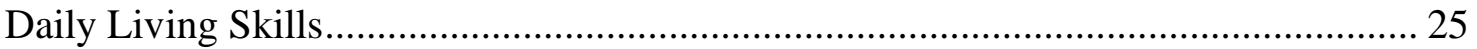

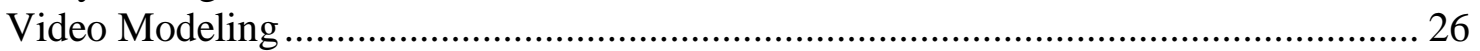

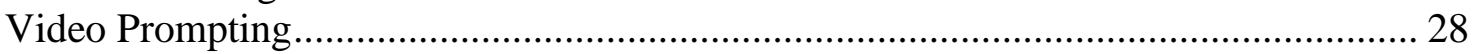

Brief Comparison of VM and VP........................................................................ 30

Continuous Video Modeling and Continuous Video Prompting.................................... 30

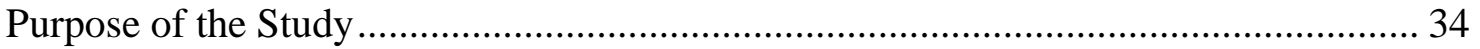

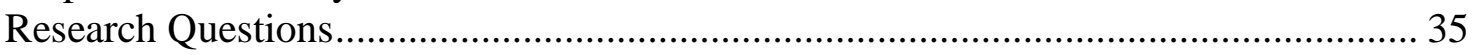

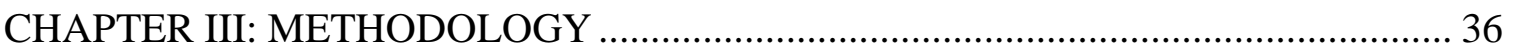

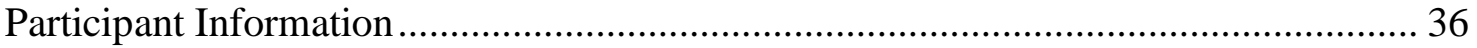

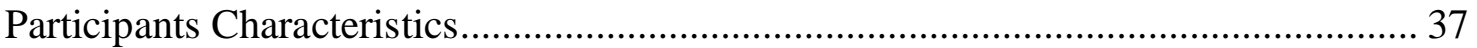

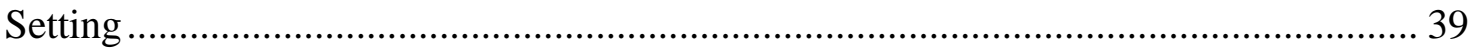

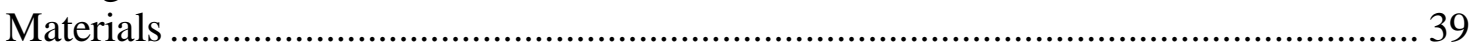

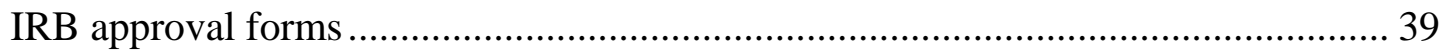

Parent consent form...................................................................................... 40

Adult participant consent form(teachers) .............................................................. 40

Child participant assent form and verbal consent form............................................. 40

Dependent variable data forms ............................................................................. 40

Interobserver agreement and treatment fidelity forms .............................................. 41

Social validity survey forms.......................................................................... 42

Preference assessment data form ......................................................................... 42

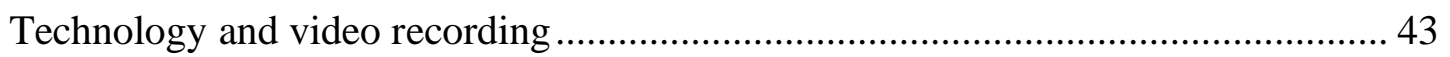

Independent and Dependent Variables .................................................................... 44

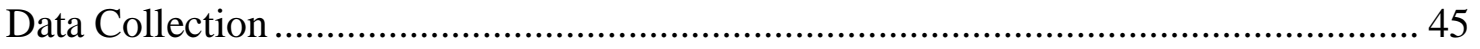

Interobserver Agreement (IOA) and Treatment Fidelity Data Collection .................... 45 


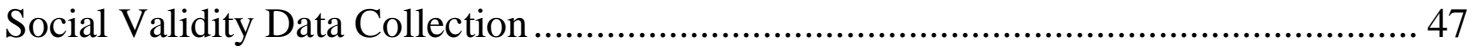

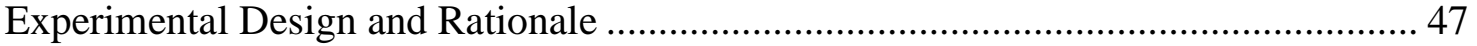

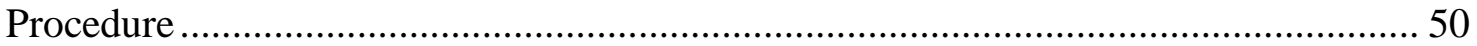

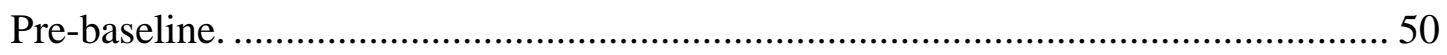

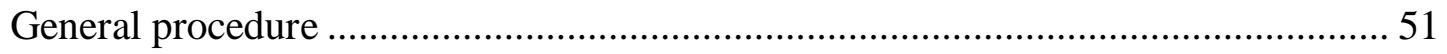

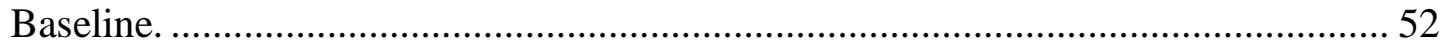

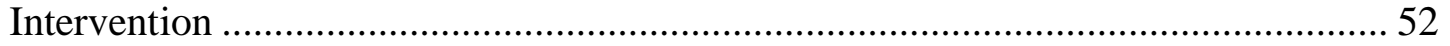

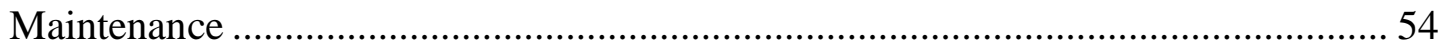

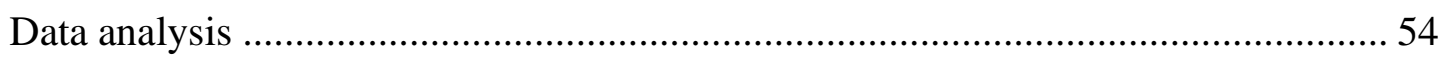

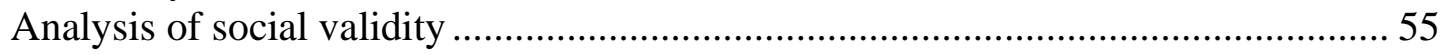

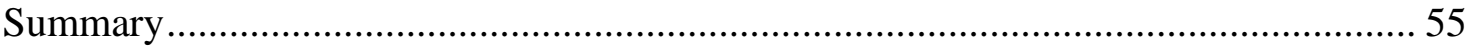

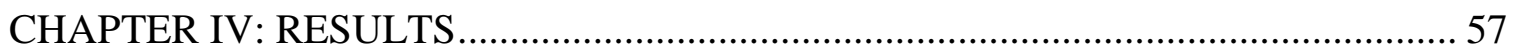

Interobserver Agreement ................................................................................... 57

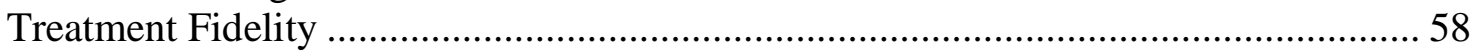

Results for Research Questions One and Two ...................................................... 58

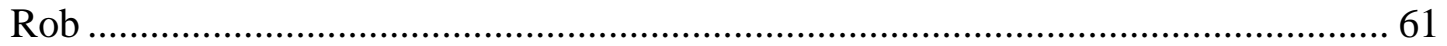

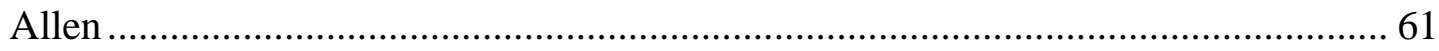

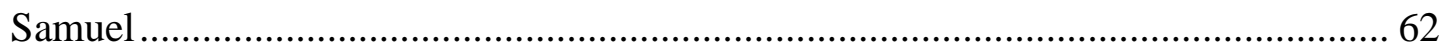

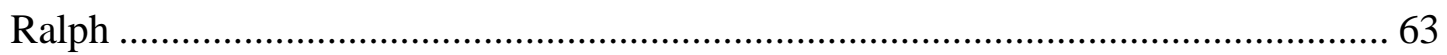

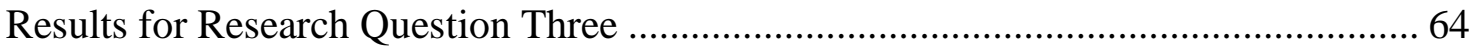

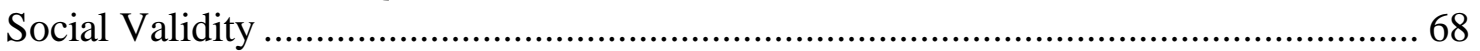

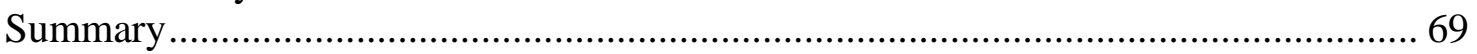

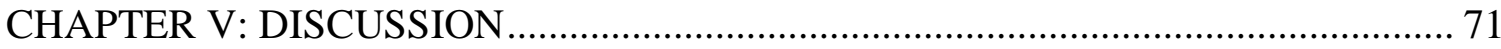

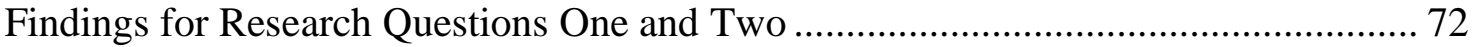

Implications for Research Questions One and Two .............................................. 77

Findings for Research Question Three ................................................................. 81

Implications for Research Question Three ........................................................ 82

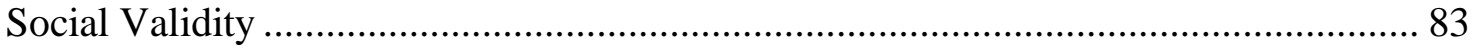

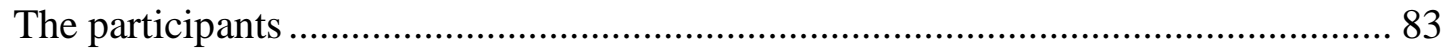

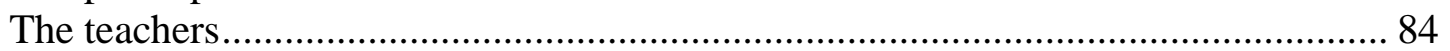

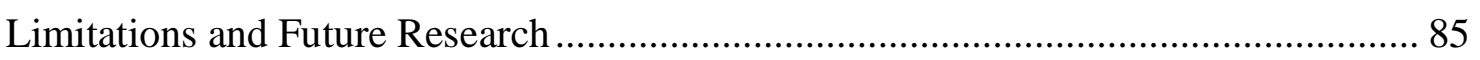

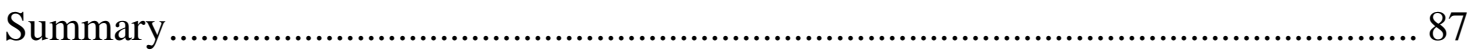

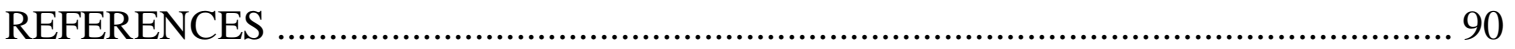

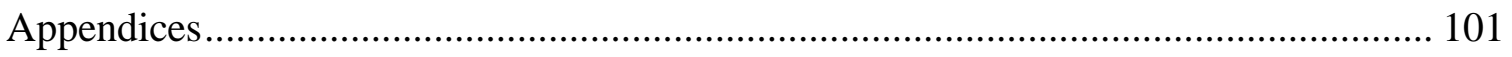

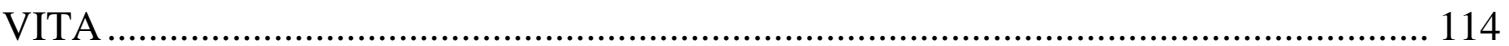




\section{FIGURES}

FIGURE

PAGE

Figure 1. Number of steps correct in the performance of the DLS ..................60

Figure 2. Mean and range of the video loops needed for viewing across

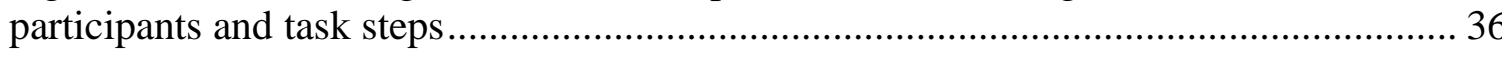




\begin{tabular}{ll} 
& ABBREVIATIONS \\
Autism Spectrum Disorder & ASD \\
Centers for Disease Control and Prevention & CDC \\
Childhood Autism Rating Scale-Second Edition & CARS-2 \\
Continuous Video Modeling & CVM \\
Continuous Video Prompting & CVP \\
Daily Living Skills & DLS \\
Developmental Disabilities & DD \\
Florida International University & FIU \\
Intellectual Disability & ID \\
Interobserver Agreement & IOA \\
Multiple Probe Design & MPD \\
Treatment Fidelity & TF \\
Video Modeling & VM \\
Video Prompting & VPI \\
\hline & \\
Video-Based Instruction & \\
\hline
\end{tabular}




\section{CHAPTER I: INTRODUCTION}

The intentions of this chapter are to offer an overview of the topic, including background information on Autism Spectrum Disorder (ASD), video modeling (VM), video prompting (VP), and focusing on the impact of continuous video prompting (CVP) for use in teaching children with ASD to improve daily living skills (DLS). The purpose of the dissertation is to provide background information on the effect of CVP on the skill acquisition among children with ASD. The first part of chapter I assesses ASD. Then, the chapter will discuss video-based instruction (VBI). Next, chapter I will provide brief information on the specific use of VP, VM, and CVP and how they have been used to improve DLS in children with ASD. Finally, the problem statement, the significance of the research, and research questions will be addressed.

\section{Autism Spectrum Disorder}

In 1943, ASD was first described by Leo Kanner on the basis of his observations

of 11 children who exhibited similar, odd behaviors (Kanner, 1943). Autism spectrum disorder is a neurodevelopmental disorder characterized by atypical deficits in socialization and communication skills, along with restrictive and repetitive behaviors and interests (American Psychiatric Association [APA], 2013; Lord \& Bishop, 2010). To diagnose ASD, clinicians use the Diagnostic and Statistical Manual of Mental Disorders, Fifth Edition (DSM-5). In May 2013, changes by the APA were made in the DSM-5 regarding the diagnosis of ASD. In the previous version, the DSM-IV-TR, there were three categorical groups of symptoms for ASD including communication deficits, social deficits, and repetitive and restrictive behaviors and interests. The DSM-5 collapsed the three groups into two groups that included social-communication deficits and restrictive 
and repetitive interests and behaviors (Esler \& Ruble, 2015). For a person to be diagnosed with ASD, the symptoms must have appeared in childhood and limited everyday functioning (APA, 2013). The DSM-IV-TR required presentation of the symptoms before three years of age, while the DSM-5 merely requires the symptoms present at an early age, no longer using three years of age as a standard (Esler \& Ruble, 2015). Again, for a child to be diagnosed with ASD, the symptoms must result in impairments in social-communication skills, as well as repetitive and restricted behavior and interests.

There are several subgroups of symptoms associated with ASD (Centers for Disease Control and Prevention [CDC], 2014). These subgroups include social-emotional reciprocity, nonverbal communication, repetitive speech and motor movement, extreme adherence to routines, and forms of verbal and nonverbal communication (CDC, 2014). A person with ASD can experience deficits in any or all of these subgroups; having deficits in the subgroups not only negatively affects the individual with ASD, but also their families (CDC, 2014). The National Professional Development Center (NPDC) on ASD pointed out that the lack of a warm, pleasant expression or gaze; not responding to his or her name; not using single words by 16 months; a delay of babbling during the first nine months of age, diminished or lack of pre-speech gestures, including waving and pointing; loss of language or social skills at any age; and repetitive movement in the first two years represent the early symptoms of ASD. According to Esler and Ruble (2015), early signs and symptoms are typically apparent in the early developmental period; nevertheless, social discrepancies and behavioral patterns might not be recognized as 
symptoms of ASD until a child exhibits social, educational, work, or other significant life stage deficits. Autism spectrum disorder is a condition that is associated with several groups of symptoms that negatively impact one or more domains of existence; some of these symptoms translate into developmental delays. Moving away from the general symptoms and developmental issues associated with ASD, prevalence can now be discussed.

\section{Prevalence}

According to Baio (2012), a complication of ASD is a lack of standardized diagnoses, creating a challenge for determining the prevalence of ASD. The CDC reported the prevalence of individuals identified with ASD among children in the United States has increased to one child in every 59, using data collected from 11 states. Generally, the ASD prevalence estimation differs by sex and ethnic group (Baio, 2012). The CDC reported that ASD is more prevalent in males than in females (CDC, 2014); ASD is around four times more common among boys than girls (CDC, 2014). Prevalence rates may also be skewed according to racial/ethnic status. According to Tincani, Travers, and Boutot (2009) there is evidence that when compared to Caucasian children, AfricanAmerican, Hispanic, Native American, and Native Alaskan children are overrepresented in the areas of Emotional Disturbance and Intellectual Disability (ID). However, AfricanAmerican children are diagnosed with ASD less often, and approximately 1-1.5 years later, than their Caucasian peers (Tincani, Travers, \& Boutot, 2009). Other evidence suggests that Hispanic and Native American children are underrepresented with diagnoses of ASD, as well (CDC, 2014). Prevalence differences across ethnic and racial 
groups should not exist as the disorder should be equal across ethnic and racial boundaries.

\section{Potential Causes}

Currently, the causes of ASD are unknown; however, what is known is that there has been an increase in prevalence in the United States, and in other nations over the past three decades (Deisher \& Doan, 2015). Today, researchers have suggested the causation of the increase in prevalence is a result of factors such as increases in awareness, services, funding and support, and new developments in identification of potential biological factors (Deisher \& Doan, 2015). Other factors that may contribute to a child developing ASD include environmental, biological, and genetic factors (CDC, 2014). Ratjczak (2011) stated that ASD might result from several causes in individuals that share common symptoms. Additionally, evidence for a genetic factor linked to ASD was first posited by Folstein and Rutter (1977). Folstein and Rutter (1977) found that 4 out of 11 pairs of monozygotic twins presented ASD, while no cases of ASD were found in 10 sets of dizygotic twins. Today, the most likely explanation is a mix of genetic and environmental factors that interact with each other causing abnormal development of the brain and neurologic systems (Kim \& Leventhal, 2015).

\section{Deficits and Strengths}

Characteristics of ASD could limit the independence of individuals, as demonstrated in the lack of functional skills among some individuals with ASD. In fact, independent performance could be difficult for people with ASD (Hume, Loftin, \& Lentz, 2009). Individuals with ASD often have difficulty completing functional tasks independently such as DLS (Van Laarhoven \& Van Laarhoven-Myers, 2006) and 
teaching these skills can be challenging for their teachers (Scott \& Bennett, 2012). A significant concern of parents and caregivers is their children's abilities to live safe and independent lives (Gardner \& Wolfe, 2015; Shipley-Benamou, Lutzker, \& Taubman, 2002). According to Carnahan, Hume, Clark, and Borders (2009), the problems associated with the lack of independent functioning of individuals with ASD create challenges in schools regarding the outcomes of student with ASD. Being able to live independently eventually is an essential quality of life issue, and unfortunately, ASD can negatively affect the development of skills needed to live independently (Carnahan et al., 2009). In reviewing the literature, a significant problem associated with individuals with ASD include imitation, which is an efficient and effective way in which most children learn (Ham, Corley, Rajendran, Carletta, \& Johnson, 2007; Heimann, Nordqvist, Strid, Connant-Almrot, \& Tjus, 2016; Kleeberger \& Mirenda, 2010). The inability to learn via imitation inhibits the learning progress of students with ASD. Another deficit associated with individuals with ASD is stimulus over-selectivity (Kelly, Leader, \& Reed, 2015; Lovaas, Koegel, \& Schreibman, 1979; Rieth, Stahmer, Suhrheinrich, \& Schreibman, 2015), which occurs when the individual focuses on only one part of an object and ignores other parts (Dube et al., 2016). Over-selectivity may affect the learning ability of an individual with ASD. An additional deficit associated with individuals with ASD is difficulty with cognition, including impairments in attention and memory (Landry \& Bryson, 2004; Mattard-Labrecque, Amor, \& Couture, 2013; Quill, 1997). Individuals with ASD have difficulties with attention and attendance to relevant details of a desired skill (Travers, Klinger, \& Klinger, 2011). Focusing on relevant details of a preferred skill expands the chance of performing the skill successfully. The learner cannot perform the 
target behavior unless he or she pays enough attention to the presented model. Increased attention is a current goal in many settings when teaching children with developmental disabilities functional skills such as brushing their teeth or getting dressed. The acquisition of attention skills for individuals with ASD is difficult, but necessary, for them to live independently (Shipley-Benamou et al., 2002).

In contrast to the aforementioned deficiencies, research has documented the ability of visual processing as a strength of individuals with ASD (McCoy \& Hermansen, 2007). Individuals with ASD seem to respond favorably when presented with visual stimuli (Quill, 1997); hence, visual supports are often used successfully with individuals with ASD (Heflin \& Simpson, 1998). Visual supports are supposedly effective because they allow the learner with ASD to link the task in his or her environment (Quill, 1997). Additionally, educators and professionals use visual supports to assist with independence and task engagement (Van Laarhoven \& Van Laarhoven-Myers, 2006). It is essential for researchers and educators to use instructional strategies that include visual supports to assist participants with ASD in learning functional skills, communication skills, and social skills. Examples of the visual strategies include photographs, line drawings, text, and structured work systems (Hume et al., 2009; Van Laarhoven, Kraus, Karpman, Nizzi, \&Valentino, 2010).

\section{Overview of Video-Based Instruction Interventions}

Over the past decade, several interventions for educating children with ASD have been developed. Intervention goals include reduction of the problem behaviors that interfere with learning, fostering growth in social abilities as well as communication skills, and learning self-help skills, among others. Recently, another visually-oriented 
intervention has gained popularity for teaching children with ASD; the intervention is video-based instruction (VBI).

As stated in the literature, VBI is a broad set of methods for use in working with individuals who have developmental disabilities. It has received considerable attention in the literature (Bennett and Aljehany 2020, Banda, Dogoe, \& Matuszny, 2011; Bellini \& Akullian, 2007; Rayner, Denholm, \& Sigfoos, 2009). According to Hong et al. (2016), VBI interventions have been used to teach numerous skills, including functional life skills, to individuals with ASD.

There are several variations that fall under the broad VBI strategy. Video modeling (VM) involves the learner watching the entire record of the performance of a target behavior before trying to imitate the behavior (Bellini \& Akullian, 2007). Video self-modeling (VSM) is similar to VM with the only difference being that the learners view themselves performing a task (Mechling, 2005). Another variation of VBI is simultaneous video modeling (SVM), where a person simultaneously completes a task while a video is playing (Blum-Dimaya, Reeve, Reeve, \& Hoch, 2010; Sancho, Sidener, Reeve, \& Sidener, 2010; Taber-Doughty, Patton, \& Brennan, 2008). Video prompting (VP) is another variation of VBI that has been used since the 1990s to help individuals with developmental disabilities (Banda et al., 2011). Video prompting is characterized by individuals watching a single clip of a video task and completing that step before watching the next video clip depicting the behavior. The strategy of VP continues until all of the tasks' sub-components have been completed (Cannella-Malone et al., 2006).

Video modeling and VP are similar strategies, but they are also slightly different in the application of their procedures (Bennett, Gutierrez, \& Honsberger, 2013). Video 
modeling has been used with individuals with special needs such as ID and behavior disorders (Cardon, Guimond, Smith-Treadwell, 2015). Moreover, VM has been effective in teaching a variety of skills to children and adults with ASD (Corbett, 2003), such as play skills (Nikopoulos, 2007), conversation skills (Scattone, 2008), and DLS (ShipleyBenamou et al., 2002). Video modeling is thought to be beneficial as a learning tool because it combines the power of observational learning with the apparent tendency of individuals with ASD to be particularly responsive to visually-cued instruction (Bellini \& Akullian, 2007). As Banda et al. (2011) commented, VM is best with short tasks that do not have many steps. It is also best used with tasks that have no steps, but rather require shaping instead of chaining. Video modeling might also be better for students with less of an impairment in intellectual functioning according to the Banda et al. (2011) study.

Video prompting, on the other hand, is more efficient for individuals with moderate to severe cognitive impairment and when the task consists of multiple steps (Banda et al., 2011). According to Tereshko, McDonald, and Ahearn (2010), VP was more effective than VM because video segments require shorter periods of attention, which allowed children to concentrate fully on the video clips. Additionally, VP has been shown to be a successful strategy for teaching individuals with ASD to complete a variety of skills. According to Banda et al. (2011) the types of skills that can be learned using VP include skills related to daily living activities and domestic skills; thus, VP may be an effective tool for teaching individuals with ASD the skills necessary for independent living.

Another type of VBI is Continuous Video Modeling (CVM) where the video does not stop after one presentation, but instead continues to play on a repetitive loop until the 
learner completes the task (Mechling, Ayres, Purrazzella \& Purrazzella, 2014). Mechling, Ayres, Purrazzella, et al. (2014) designed a study to address the limitations of other VBI studies related to the characteristics of the participants and the delivery of the video format. That is, in traditional VM, participants watch the video, the video ends, and then participants attempt to complete the task. With CVM, however, the video continues to play in a repetitive manner while the participants complete the tasks. With CVM, the video remains as a constant prompt to help students who might struggle with deficits in working memory. These researchers were examining CVM to teach individuals with development disabilities to complete a chained task. Participants in the study conducted by Mechling, Ayres, Purazzella, et al. (2014) experienced disabilities that included Down syndrome, moderate intellectual disability, and hearing impairment. Mechling, Ayres, Purazzella, et al. (2014) concluded that CVM may be more effective than watching the whole video and then attempting to complete a lengthy task, as well as being more efficient than stopping and starting the video, as in VP, which could interrupt the flow of task completion. They speculated that CVM might promote self-instruction, as an individual is able to go back to the instructional video at any time. There were, however, limitations to the Mechling, Ayres, Purazzella, et al. (2014) study. First, in terms of $\mathrm{CVM}$, it is unknown whether or not CVM is more effective than VM as the researchers did not run a comparison between these methods. Second, tasks involving repetitive steps were selected for the CVM study; these tasks included folding multiple sizes of towels, setting a buffet table, and in sorting recycling materials. Each of the tasks included multiple steps; however, these steps repeated as the participants completed the tasks (e.g., 
folding a small bath towel consisted of four steps, and these steps repeated each time these towels were folded; Mechling, Ayres, Purazzella, et al. 2014).

A second CVM study by Mechling, Ayres, Bryant, and Foster (2014) extended the findings of the first study by teaching a task with multiple steps, but without repetition of task steps, to young adults with disabilities. Participants experiencing disabilities such as ASD, ID, Prader Willi Syndrome, and Down syndrome participated in the study. Tasks included cleaning an exercise bicycle, cleaning an area rug, and washing kitchen counters. The task steps in Mechling, Ayres, Bryant, and Foster (2014) study did not repeat themselves as in the previous study whereby participants folded towels. Rather, each step was unique in presentation. The researchers reported positive results for two of the three participants; however, there were noted limitations. Participants had difficulty performing the correct steps when a different clip of the video was playing relative to the step on which they were working. Additionally, participants had difficulty finding the right step on the video when the entire video repeated back to the beginning. In fact, Mechling, Ayres, Bryant, et al. (2014) reported that two of the participants asked the teacher to stop the video when they were unable to follow or view the step on which they were working.

The aforementioned studies by Mechling Ayres, Purrezzlla, et al. (2014) and Mechling, Ayres, Bryant, et al. (2014) involved task learning and the use of CVM to teach and improve the skills of the participants. The studies used participants with differing developmental levels, with at least one participant being specifically diagnosed with ASD; none of the participants were children. Finally, both CVM studies showed that CVM was a successful strategy for individuals with moderate ID. Although these 
researchers obtained successful results with the use of CVM, both studies reported limitations that represent gaps in the literature.

In response to the shortcomings of CVM, Cannella-Malone et al. (2015) explored a variation of CVM by combining it with features of VP. Continuous Video Prompting (CVP) involves an individual watching a single clip of a video that presents a task with the learner having to complete that step before watching the next video clip. The single video clip repeats until the learner completes the step. Once that step is completed, the video advances to the next step. Thus, the potentially advantageous video looping features of CVM are combined with the single task step viewing of the VP strategy. In the Cannella-Malone et al. (2015) study on CVP, the researchers examined its effectiveness on teaching a single16-year-old learner with ASD and ID how to clean a table, wash windows, and wash dishes. The researchers found that CVP was effective, but it had to be combined with other intervention procedures such as error correction. Notwithstanding the positive outcome of the Cannella-Malone et al. (2015) study, the use of additional intervention strategies represents a limitation to the study as it is not known whether CVP by itself would be effective for students. Moreover, the researchers examined CVP with one participant, and therefore, the external validity of the findings is limited at this time. Finally, the researchers did not count the number of times the video looped for each step. Thus, it is not known how many presentations were needed before the participant attempted task step completion. These three limitations present a gap in the literature to be addressed. 


\section{Statement of the Problem}

The limitations in both studies on CVM research reveal a gap within this field of study. There are several limitations apparent in the literature on CVM. Mechling, Ayres, Purrazzella, et al. (2014) indicated that the inclusion of repetitive chained tasks and lack of maintenance data were some noteworthy limitations to their study. Additionally, Mechling, Ayres, Bryant, et al. (2014) stated limitations to their use of CVM included tasks not being counterbalanced, issues with training, task difficulty, inability of participants to hear instructions over noise, and an unfamiliarity with CVM on the part of the participants. Cannella-Malone et al. (2015) also noted other potential limitations with CVM, and these limitations included participants with more severe disabilities not being able to keep up with the steps and confusion over the steps.

The literature on CVP also demonstrated limitations in the research. CannellaMalone et al. (2015) stated limitations to their work included researchers not counting the cycles it took participants to complete the tasks and not knowing if CVP with error correction was responsible for the participant learning skills. Given these issues, additional research should be conducted to determine the effectiveness of CVP. Moreover, none of the research encountered utilized the interventions with younger preadolescent to adolescent children with ASD. Because of the limitations mentioned previously, the present study will focus on the use of CVP with children with ASD.

The study addresses some of the issues and limitations of the Canella-Malone et al. (2015) study. First, the researcher will count the number of cycles of CVP throughout the current experiment to determine the number of cycles it takes participants to complete tasks correctly. With this knowledge, it will be possible to know if CVP or traditional VP 
produces the results. The Canella-Malone et al. study added additional support for the use of CVP including error correction with prompting. It was not possible to determine if the results of the experiment were from CVP alone, or some other intervention component that Canella-Malone et al. added to the study. Additionally, the Canella-Malone et al. study included one 16-year-old female with ASD and ID. Because of the issues with the Canella-Malone et al. study, the current study is designed to use CVP alone for five cycles with children with ASD to teach them a DLS.

\section{Purpose of the Study}

The purpose of the present research is to narrow the gap in the literature regarding the use of CVP with children with ASD. In the current literature, there are only two studies that addressed the effectiveness of CVM on teaching DLS to those with mild to moderate ASD and ID (i.e., Mechling, Ayres, Bryant, et al. 2014; Mechling, Ayres, Purrazzella, et al. 2014). Although these studies demonstrated positive outcomes with the use of CVM, the method may be less effective when used with individuals with disabilities when the targeted tasks are lengthy, paralleling issues known with traditional VM (Banda et al., 2011). Canella-Malone et al. (2015) attempted to correct these potential issues of CVM by implementing a modified version called, CVP. However, the Canella-Malone et al. (2015) study only included one participant, consisted of multiple interventions, and lacked data on how many viewings of the video the participant watched prior to task completion. The current study measures the effectiveness of using CVP alone for five cycles to teach DLS to children with ASD, aged 11-14 years. Results of the study will contribute to the literature, as well as expand the knowledge of the effectiveness of CVP alone when working with children with ASD. 


\section{Research Questions}

The research questions are as follows:

1. Is CVP an effective strategy to teach DLS to children with ASD (aged 1114 years) without the use of additional response prompts?

2. If improvement in skill acquisition is observed, to what extent will the skills be maintained once the intervention is removed (i.e., weekly interval for three weeks following the conclusion of (VP)?

3. How many video segment loops need to be played for the participants to learn each step of the selected task?

\section{Summary}

Autism spectrum disorder was first described by Kanner in 1943. The disability is characterized by deficiencies in the areas of social-communication and repetitive and restricted behaviors and interests. In the years since ASD was described, much has changed. For example, while the exact cause of ASD is unknown, it is clear that ASD affects boys at a higher rate than girls, and is most likely the result of several factors, including genetic and environmental factors interacting together.

Teaching children with ASD is quite a challenging task because of the skill deficits related to the symptoms of the disability. Teaching activities of daily living to those with ASD is difficult but important as it is these activities that will allow them to live independent lives. Some of these skills include preparing meals, tying shoes, cleaning the house, and brushing teeth. The importance of these skills cannot be overstated. 
Current research has focused on interventions used for teaching individuals with ASD and developmental disabilities. Video based instructions is on the forefront of effective interventions. Video based instructions is a set of interventions that involve teaching through the use of video. Variations of VBI include VM, VSM, VP, CVM, and CVP, to name a few. Some VBI methods have shown to be effective, while other methods of VBI have had mixed results. Some of the research has demonstrated efficacy in teaching individuals with severe disabilities using VBI techniques; moreover, some specific interventions have demonstrated greater efficacy than others. Recent variations of VBI, including CVM and CVP have shown promising results but with limitations. A noted limitation of CVM was that participants became confused as to when a repeating video segment did not match the step on which they were attempting to complete. Moreover, limitations to CVP included the number of video loop cycles, which were not counted; thus, it is not known if a single display of a video step evoked student responses or if multiple displays of the video step were needed. Additionally, and more at issue, additional response prompts were used as part of the error correction procedure while implementing CVP. Thus, in the Cannella-Malone et al. (2015) study, CVP consisted of an intervention package with multiple components. It is therefore, not known, which of these components were responsible for behavior change. Finally, the use of CVP has not been examined with younger participants with ASD.

These issues represent gaps in the literature. The purpose of the present study was to examine the effectiveness of CVP alone in teaching DLS to children with ASD, aged 11-14 years. In the CVP procedure for this research, the video includes five repetitions of 
video cycles to determine the effectiveness of CVP for teaching (DLS) to younger adolescents with ASD.

\section{Operational Definitions}

Autism Spectrum Disorder (ASD): a group of neuro-developmental disorders characterized by typical deficits in socialization skills; communication skills; and restricted, repetitive, or stereotyped behaviors (APA, 2013).

Video Based Instruction (VBI): a set of interventions that have been used to teach individuals with developmental disabilities. These interventions typically involve some type of video that breaks down the steps of a task. Video-based instruction includes Continuous Video Modeling and Continuous Video Prompting. The videos used for VBI can be filmed from different points of view, such as first-person point of view or thirdperson point of view.

Video Modeling (VM): a VBI strategy that involves the participant watching the entire recorded performance of the target behavior before they imitate the viewed behavior (Mechling, 2005).

Video Prompting (VP): a VBI strategy that involves the participant watching a segment of a task before imitating what was viewed; this sequence repeats until the entire task has been attempted or completed.

Continuous Video Modeling (CVM): an intervention delivered via video wherein the video plays in a repetitive loop, allowing the participant to see all steps of the task multiple times as he or she is attempting to complete the skill.

Continuous Video Prompting (CVP): an intervention wherein an individual watches a single step on a video clip that repeats as he or she is performing the step. Once the step 
has been completed, the video advances to the next step and plays on a repetitive loop until that step is finished (Cannella-Malone et al., 2015).

Daily Living Skills (DLS): skills required for everyday independent living (Flynn \& Healy, 2012). 


\section{CHAPTER II: LITERATURE REVIEW}

This section reviews the literature describing the history of Autism Spectrum Disorder (ASD), the diagnosis of ASD, a summary of the prevalence of ASD as reported by the Center for Disease Control and Prevention (CDC, 2009, 2014, 2020) in the United States, and the characteristics of ASD. The three areas of deficits in social skills, communication skills, and restricted and repetitive behaviors and interests will be discussed, as well as the strengths of children with ASD. Finally, video-based instruction (VBI) including a literature review on the use of video modeling (VM), video prompting (VP), and continuous video prompting (CVP) that have been used with individuals with ASD teaching DLS are presented.

\section{The Background and History of ASD}

The term autism comes from the Greek word "Autos", which translates to the word "self" in English (Hall, 2013). Eugene Bleuler (1911) first used this term to define a subset of individuals with schizophrenia, who isolated themselves and withdrew from the world (Sicile-Kira, 2004). Subsequently, Leo Kanner (1943) described a group of 11 children who were all highly intelligent, desired being alone, displayed obsessive behaviors, and preferred persistent sameness. Both psychologists described attributes that led to a definition of ASD published by the American Psychological Association (APA) in the Diagnostic and Statistical Manual of Mental Disorders.

According to the American Psychological Association (APA, 2013), ASD is set of neurodevelopmental disorders wherein there is impairment in communication and social interaction, as well as repetitive and restricted behaviors that affect individuals

across their lifetime. These deficits are characterized by social communication and social 
interaction difficulties including problems in developing, maintaining, and even understanding relationships; these deficits are typically manifested by three years of age (APA, 2013; Landa, Holman, \& Garrett-Mayer, 2007; Lord \& Bishop, 2010; Napolioni et al., 2011). The APA (2013) further states that the severity of ASD must be considered in the diagnosis in relation to the level of social communication impairment and patterns of restrictive and repetitive behavior, as well as the child's level of intellectual and/or language ability.

According to the CDC (2020), diagnosing ASD can be challenging because there is no medical test to identify individuals with ASD. Without a medical diagnostic test, doctors must rely on methods based on comparing the child's behavior to typical developmental milestones. It is thought that ASD is now diagnosed earlier than in the past due to parental concerns, increased awareness of ASD by educators and professionals, and the general public awareness (Wolff, 2004).

According to Hall (2013), disagreements ensued over many years while aiming to determine the causes of ASD. Prior to Kanner's work in the 1940s, it was generally accepted that poor parenting skills and behavior caused autism; Hall further states that Kanner contributed to this line of thinking by specifying a maternal cause related to interactions (Hall, 2013). In the 1950s, Bruno Bettelheim attributed ASD to "frigid" mothers who did not show proper warmth and caring to their children, and in turn, the children turned inward; this had devastating effects on families and potentially delayed the development of appropriate treatment options for the children (Scott, Clark, \& Brady, 2000). In 1964, Rimland attributed ASD to biological factors (Hall, 2013). It is now known that a familial history of ASD increases the risk of receiving a diagnosis of ASD 
by $15 \%$ to $20 \%$ in children within the family (CDC, 2014; Dawson et al., 2002; Lamb, 2011). With causes of ASD still unknown, much has been written about interacting factors potentially influencing the increasing risk of ASD including genetics, environment, mother's age, and father's age. However, the most current findings of possible causes of ASD is an interaction of genetic and environmental factors that cause abnormal brain development (Kim \& Leventhal, 2015).

The prevalence of ASD is monitored through surveillance activities by the Autism and Developmental Disabilities Monitoring Network (ADDM; CDC, 2009). The prevalence of ASD in the United States is 1 in 54 in children who were 8 years of age based upon the most recent data collected during 2016 (Maenner et al., 2020). Eight-yearold males were four times more likely to have ASD than females (CDC, 2014). During 2010-2012, the prevalence of ASD among children eight years old was 1 in 68 (CDC, 2014). In comparison, for the year 2008, the prevalence rate was 1 in 88 children at eight years old (Baio, 2012). For the year 2006, the estimate was 1 in 110, and for the year 2000, it was 1 in 150 children (CDC, 2009). This increase illustrates there was a rapid rate of growth in the prevalence of ASD over recent years. Hattier and Matson (2012) stated that it is unknown if the prevalence rate for ASD is increasing because more people actually have ASD or if the increase is due to improved diagnostic tools; with the previous statement, it can be assumed the increasing prevalence rate is due to both.

According to Steroni and Shankey (2013), the symptoms associated with ASD interfere with language skills development. Goodson, Sigafoos, O'Reilly, Cannella, and Lancioni, (2007) stated that even small changes to the routines of individuals with ASD result in extreme distress for the person with ASD, which in turn, interferes with the 
acquisition of skills required for daily living routines. Elser and Ruble (2015) noted those with ASD are extremely sensitive to their environment and often display hypo- or hyperreactivity to sensory input, or an unusual interest in the sensory aspects of their environment.

It is unequivocal that ASD adversely affects attention, memory, imitation, and information processing for individuals (Hiemann et al., 2016; Kleeberger \& Mirenda, 2010; Landry \& Bryson, 2004; Mattard-Labrecque et al., 2013; Quill, 1997). In fact, imitation skills are extremely impaired in many children with ASD; however, many ASD interventions rely on imitation skills (Smith, Lowe-Pearce, \& Nichols, 2006). Strengthening the imitation skills of individuals with ASD is of the greatest importance (Cardon \& Wilcox, 2011). For example, VBI interventions rely heavily on imitation skills because learners use the video instruction as a model to imitate the skill (Kleeberger \& Mirenda, 2010). Moreover, VBI also relies on the ability to pay attention on the part of the learner. In fact, all modeling techniques rely on this (Bandura, 1977).

Stimulus over-selectivity is another deficit faced by individuals with ASD (Kelly et al., 2015; Reith et al., 2015). Stimulus over-selectivity leads the children to overfocusing on a small subset of stimuli, which might affect learning (Lovaas et al., 1979). Learners with ASD often concentrate on things outside of what is being learned, which obstructs learning (Dube et al., 2016). Memory deficits are also an issue for people with ASD, as well as difficulties memorizing complex, multi-step tasks (Boutot \& Myles, 2011). One VBI tactic that addresses the memory deficit of individuals with ASD is VP. According to Cannella-Malone et al. (2006), VP uses short video clips to help the participant concentrate on the targeted skills for a short period of time. After completing 
a step, the learner can move on to the next step of the video, and this process seems to accommodate the noted issues with memory (Cannella-Malone et al., 2006). With VBI, individuals with ASD can see the clip over and over, in different settings, until mastering the targeted skills; live modeling may not provide these benefits (Gardner \& Wolfe, 2013). However, individuals with ASD often focus on things irrelevant to the successful completion of targeted skills, and this relates to the aforementioned issue of stimulus over-selectivity (Bellini \& Akullian, 2007). Thus, VBI can be used to reduce external stimuli by minimizing irrelevant stimuli in the environment, which would support learning (Barton, Lawrence, \& Deurloo, 2012; Sherer et al., 2001).

There is a strength related to learning for individuals with ASD. Individuals with ASD have strong visual perception skills and seem to learn best when information is presented visually (Kellems \& Morningstar, 2012; McCoy \& Hermansen, 2007; Quill, 1997). In fact, individuals with ASD might have stronger visual perception skills than auditory skills (Quill, 1995). Visual cues aid persons with ASD not only in learning but in organizing and making sense of their environment (Heflin \& Simpson, 1998; Hodgon, 1995; Simpson \& Myles, 1998).Visual stimuli including photographs, line drawings, text, and visual cues have been used to teach daily living activities to those with ASD (Nietupski, Clancy, \& Christiansen, 1984; Nietupski, Welch, \& Wacker, 1983; Pierce \& Schriebman, 1994; Van Laarhoven et al., 2010). Currently, another visual support that has gained acceptance for teaching individuals with ASD is VBI, which seeks to use the strengths of individuals with ASD to teach them DLS. According to Bellini and Akullian (2007), strong visual perception among individuals with ASD is an important factor to 
increase the effectiveness of VBI strategies for teaching skills by performing them after watching video clips.

\section{Video-Based Instruction}

Video-based instruction is a term used in the literature to describe a group of interventions aimed at teaching individuals with developmental disabilities and individuals with ASD. The interventions classified as VBI use some type of video clip to aid in the transference of knowledge to the learner (Ayres \& Langone, 2005; Bellini \& Akullian, 2007). According to Bellini and Akullian (2007), VBI is a commonly used intervention for teaching individuals with ASD. VBI has shown efficacy in teaching those with ASD to support retention processes (Ayres \& Langone, 2005). According to Bellini and Akullian (2007), the strong visual perception of individuals with ASD was an important factor in increasing the effectiveness of VBI strategies used to teach skills by performing targeted steps after watching video clips. Video based instruction has been shown to effectively teach appropriate behaviors and activities of DLS to learners with ASD (Banda et al. 2011; Bellini \& Akullian, 2007; McCoy \& Hermansen, 2007). McCoy and Hermansen (2007) further state that VBI has been effective teaching learners from preschool age to adulthood. Furthermore, VBI has been used in several settings including the special education environment, the general education environment, at homes, and in clinics (Wong et al., 2015). Video based instruction has been demonstrated to be effective in teaching individuals with ASD alone and when combined with another intervention such as the Social Story (Scattone, 2008). Video based instruction could also be implemented as a treatment package that might include response prompting including least-to-most prompting, graduated guidance, error correction, and voice-over narration 
(Banda et al., 2011). Whatever the combination of strategies, VBI interventions rely heavily on the learner's ability to pay attention, as well as to imitate skills (Banda et al., 2011; Kleeberger \& Mirenda, 2010).

\section{Theory of the Study}

In general, VBI is based upon the work of Albert Bandura; both VM and VP rely heavily on this theory. According to Jarvis, Holford, and Griffin (2003), Bandura was concerned with how human beings learn. Over 40 years ago, Bandura discussed the concept of modeling, a key aspect of Bandura's Social Learning Theory, in which observational learning occurs (Bellini \& Akullian, 2007). Social Learning Theory links the modeling of behavior with learning through observation (Bandura, 1969; Bandura, 1977). In observational learning, the learner observes a model, this observation is processed cognitively, and this processing produces behavioral change (Bandura, 1986). In simple terms, a person watches other engaged in a behavior and this leads them to behave similarly. In addition, behavior learned through observational learning can be reinforced (Gies \& Porretta, 2015). For example, a person watches a group of people exhibiting a certain behavior, and then that person begins to imitate the observed skills and perform the skills. That performance will lead to either positive or negative reinforcement, which increases the learner's behavior. Hence, Bandura understood that observational learning was an additional aspect of learning theory.

According to Bandura (1986), four processes work together in observational learning: attention, retention, production, and motivation. Bandura (1986) defines attention as the initial act of attending to the perception of some event. According to Schunk (2012), retention is the process wherein what is observed is cognitively 
organized, codes are rehearsed, and modeled information is transformed. In other words, retention is the capacity of the learner to process the modeled behavior in memory, through verbal encoding and visual imagery (Corbett, 2003). The production process occurs when the learner rehearses and reproduces the behavior of the model (Gies \& Porretta, 2015). In addition, reproduction involves translating visual and symbolic conceptions of events into behavior (Schunk, 2012). The last step is motivation, which refers to learning that occurs in the presence of reinforcement. In VP, the learner is motivated to reproduce the observed skills after watching the clip, which reinforces or rewards the participant. Bandura advocates for the use of rewarding learners for approximation and critical thinking; in the classroom, rewards are often given as part of the modeling process. An example of this would be praising a student for performing something correctly.

\section{Daily Living Skills}

An essential component of the study is DLS. According to Flynn and Healy (2012), DLS are the types of skills necessary for independent living. Mosey (1986) states that these skills contribute greatly to daily life. Cronin (1996) determined that the ability to engage in DLS allows a person to perform life independently during adulthood. Daily living skills are functional skills. These skills, and the importance of teaching these skills to individuals with disabilities, have been acknowledged by professionals for decades (Ayers et al., 2011; Brown et al., 1979). By learning DLS, individuals can cope with and succeed in their environment (Test, Aspel, \& Everson, 2006; Volkmar \& Wiesner, 2009). Typical DLS includes skills such as brushing one's teeth, using public transportation, tying one's shoes, and going grocery shopping, to name a few. According to Hong et al. 
(2016), individuals with ASD often have difficulty acquiring DLS. This lack of acquisition of these skills negatively impacts the ability to live and work independently. According to Hendricks and Wehman (2009), adults with ASD who have not acquired these skills have problems with their home lives, as well as problems participating in their communities. The acquisition of DLS is also a concern of parents of children with disabilities, including ASD, because they want their children to live productive and independent lives (Shipley-Benamou et al., 2002). The timing of DLS acquisition is important. Pierce and Schreibman (1994) state that acquiring these skills earlier in life makes an individual more successful in both domestic and vocational settings. According to Shipley-Benamou et al. (2002), the acquisition of these skills by children with ASD can greatly reduce some of the burdens their caregivers face. Thus, with the many benefits associated with the acquisition of DLS, it is important to teach individuals with ASD to achieve maximum independence.

It should be a priority for the educator to provide effective interventions. There are several interventions that have been used to teach these skills to individuals with ASD and ID. These interventions include most-to-least prompting (e.g., Batu, Ergenekon, Erbas, \& Akmanoglu, 2004), VM (e.g., Keen, Brannigan, \& Cuskelly, 2007), and VP (e.g., Sigafoos et al., 2005), to name a few. Efficacy using VP has been demonstrated teaching DLS to individuals with ASD (Banda et al., 2011); the intervention herein is a variation of VP that is called continuous video prompting (CVP).

\section{Video Modeling}

Video modeling (VM) is a type of VBI—based on Bandura's concept of observational learning - that has been used effectively to teach and improve the skills of 
learners with developmental disabilities (Mechling, 2005; Sigafoos et al., 2007; Rayner et al., 2009).Video modeling has been widely used over the past few decades to teach individuals with DD, including those with ASD (Paterson \& Arco, 2007). In VM, learners watch an entire video in which a model demonstrates an activity. This model could be an adult, sibling, peer, or even the individual him/herself; the learner then imitates, or attempts to imitate, the targeted skills (Delano, 2007). Research has demonstrated that VM is effective in teaching skills regardless of the model (Ayers \& Langone, 2007; Rayner et al., 2009; Shukla-Mehta, Miller, \& Callahan, 2010). Moreover, according to Mechling (2005), the videos used during VBI can be shot from different points of view; specifically, the video can be shot from the perspective of someone watching the other person performing the activity, or from the perspective one would experience while performing the activity themselves.

Due to the aforementioned features of VM, it can be individualized to each learner (Delano, 2007). Consequently, VM has been used successfully when teaching individuals with DD, including ASD, skills and behaviors including reducing problem behavior, improving functional skills, improving communication and social skills, and promoting perspective-taking skills, to name a few (Corbett, 2003; Dorwick \& Jesdale, 1991; Delano, 2007, Irwin, 1981; Webster-Stratton, 1990). Video modeling is also known for its effective development of generalized skills that maintain following the removal of the intervention since a wide variety of behaviors and settings can be incorporated (Corbett, 2003). In addition, greater control of the modeling procedure can be applied with the use of video (Corbett, 2003). The videos can be viewed and reviewed multiple 
times by the learner; the learner is exposed to the same model doing exactly the same activity or exhibiting the same behavior repeatedly (Corbett, 2003).

Simultaneous Video Modeling (SVM) is another version of VM in which learners simultaneously perform the task while watching the video (Sancho et al., 2010; TaberDoughty et al., 2008). There are a limited number of studies on SVM (Mechling, Ayers, Purrazzella, \& Purrazzella, 2014). In two SVM studies, one conducted by Taber-Doughty et al. (2008) and another by Sancho et al. (2010), the researchers compared the effect of VM and SVM. Taber-Doughty et al. (2008) compared SVM using a video on an iPod to delayed VM on a computer. These strategies were utilized to support students developing the skill of using library systems to locate books and DVD video recordings. The results showed that both strategies were effective systems for increasing independent performances for two students, but it was also found that learner preferences were also a factor in the effectiveness of the modeling style. Learners that prefer one modeling technique over another may have better learning outcomes when their preferred technique is used. In the second comparison study, Sancho et al. (2010) found no significant differences between SVM and VM in the performance of one participant with ASD; although, SVM was more effective for the second student with ASD for the acquisition of play skills.

\section{Video Prompting}

Video prompting (VP) is another type of VBI intervention that is closely related to VM. VP breaks down tasks into several steps and learners attempt each step before viewing the next step (Banda et al., 2011). The VP strategy addresses the potential shortterm memory deficit of individuals with ASD. According to Cannella-Malone et al. 
(2006), VP uses short video clips to help the participant concentrate on targeted skills for a short period of time. For example, after learning a step, the learner can move to the next step of the video, which could accommodate issues with short-term memory and help the individual complete skills (Cannella-Malone et al., 2006). Video prompting differs from VM by breaking down tasks into several steps, with learners attempting each step before viewing the next step, rather than expecting the learner to watch the entire process before attempting all the steps together (Banda et al. 2011).

Video prompting is an evidenced-based instructional strategy that can be used to enhance the acquisition of functional skills for participants with DD (Gardner \& Wolfe, 2013). In an early example, Sigafoos et al. (2005) studied VP and its application for teaching three adults, two with moderate ID and one with ID and ASD, how to make popcorn. The intervention was delivered alone, with neither feedback nor error correction (Sigafoos et al., 2005). Two participants learned this skill and they maintained it for up to 10 weeks after withdrawal of the intervention (Sigafoos et al., 2005). The third participant failed to reach criterion using VP; therefore, VP might not have been effective in fostering this skill for this adult (Sigafoos et al., 2005). Overall these data provide some support to teach DLS to adults with DD using VP. In a later example, Edrisinha, O’Reilly, Choi, Sigafoos, \& Lancioni, (2011) used VP alone without either feedback or error correction to teach four adults with DD how to take digital pictures and print them using a laptop and printer. The results of this study showed that all the participants learned the skills (Edrisinha et al., 2011). Finally, in a more recent example, Bennett, Gutierrez, and Loughrey (2016) examined the use of VP to teach adolescents with ASD office and vocational tasks. Each participant demonstrated improvement in their skill 
development and participant's abilities maintained several weeks following intervention. Thus, the use of VP is encouraging because it has been applied to help individuals in need to achieve mastery of multiple DLS.

\section{Brief Comparison of VM and VP}

Video prompting and VM are both VBI-type interventions and are quite similar (Cannella-Malone et al., 2006; Gardner \& Wolfe, 2013). One major difference between the two interventions is that while VM videos show the entire task from beginning to end before requiring a student to attempt the skill, VP videos are broken down into individual steps that the learner watches before attempting to complete each task step (CannellaMalone et al., 2006; Gardner \& Wolfe, 2013).

\section{Continuous Video Modeling and Continuous Video Prompting}

Another tactic of VBI is continuous video modeling (CVM). In CVM, the learner watches a video while he/she undertakes completing the task demonstrated in the video; simultaneously the video automatically replays repeatedly until the participant completes the task (Mechling, Ayres, Bryant, et al., 2014; Mechling, Ayers, Purrazzella, et al., 2014). Thus, in CVM the video plays repeatedly until the targeted skills are completed. It may take several loops of the video for the learner to complete the task (Mechling, Ayres, Purrazzella et al., 2014). The procedures are similar to SVM, with the person simultaneously completing a task while a video is playing (Sancho et al., 2010). Continues video modeling differs from SVM in that when using CVM, the video does not stop after one viewing, but instead, plays in a continuous loop, repeating itself until the individual completes the task. This allows the participant to refer back to the video to observe the steps to be completed. Participants can complete steps of a task at the same 
time as the video plays, or they can wait for the video to loop around to provide needed visual information for finishing a step (Mechling, Ayres, Bryant et al., 2014).

In the first study evaluating this variation of VM, Mechling, Ayres, Purrazzella, et al. (2014) used CVM to teach four participants with Down Syndrome and moderate ID how to complete the following tasks: folding several different sizes of towels, sorting recycling material, and setting a buffet table that had multiple stations for serving. A point-of-view perspective was used for the videos, and there were voiceover instructions explaining the steps. The only prompts from the instructor were to inform the learner to bring his/her attention back to the video or to wait before continuing. The study showed that the use of CVM in teaching tasks to individuals was supported, as three of the four participants completed the tasks (Mechling, Ayres, Purrazzella, et al., 2014). Mechling, Ayres, Purrazzella, et al. suggested that the use of CVM may be more efficient than VM because there is no need to stop the video and start a clip over; this form of VBI may aid with independent learning and completion of tasks. In addition, CVM may promote selfinstruction as the person is able to refer back to the video at any point for assistance, demonstrating the potential efficacy of CVM (Mechling, Ayres, Purrazzella, et al., 2014). However, it was noted that one problem area of this approach was that participants had difficulty performing steps correctly when a different step was shown on the video compared to the step on which they were currently engaged (due to the looping nature of CVM). Moreover, participants had difficulty finding the right step to view once the video looped (Mechling, Ayres, Purrazzella et al., 2014). To illustrate these issues, Mechling, Ayres, Purrazzella, et al. (2014) stated that two of the participants asked the instructor to 
stop the video when they were unable to keep up with what was being presented relative to the task step in which they were engaged.

In another CVM study that extended the first study, Mechling, Ayres, Bryant, et al. (2014) used CVM to teach three adult learners with moderate ID the following tasks: cleaning an exercise bike, vacuuming and shampooing an area rug, and cleaning kitchen counters. In this study, the researchers used CVM to teach participants to complete multistep tasks whereby task steps did not repeat. This differed from the original study by Mechling, Ayres, Purrazzella, et al. (2014) whereby the researchers used CVM to teach participants a task where the steps repeated during a session (i.e., folding a towel). In this study, Mechling, Ayres, Bryant, et al. (2014) evaluated the effectiveness of CVM with voiceover narration to describe what was being done, across tasks, for each participant. The findings support the effectiveness of CVM in teaching learners with moderate ID as all the participants experienced improvement over baseline in completing tasks independently. However, while all participants saw some improvement, two of the three participants saw greater levels of improvement than did the third participant. It was also found that tasks with non-repetitive steps were easier to learn, but it is unknown if CVM is more effective than other strategies for these types of tasks. It is possible that there are some skills that users need to learn in order to take advantage of CVM (Mechling, Ayres, Bryant et al., 2014). From the data and results, Mechling, Ayres, Bryant, et al. (2014) posited that different learning preferences could impact the effectiveness of CVM. Interestingly enough, it was also found that the participants only watched and listened initially, and in later sessions, began to rely more on listening to the videos as they completed the steps rather than watching them. 
Notwithstanding these findings, there are several important limitations with the second study. First, it is unknown if when problems learning the task arose due to a lack of understanding of the process or difficulty of the task. Second, the noise from the use of the vacuum cleaner may have made it difficult for learners to hear the video instructions. Finally, the participants were familiar with VBI, but not specifically with CVM (that included lack of history training for using CVM and failure to balance the order of the task across the learners), and this could have influenced the results. An analysis of the results from both CVM articles indicates that additional research is needed on the effects of CVM on the skill acquisition of learners with ID and/or ASD. The results from both studies potentially demonstrated that the types of tasks being performed by the participants may have influenced the effectiveness of CVM (Mechling, Ayres, Bryant et al., 2014). Moreover, a recurrent theme with CVM is that learners could not always keep pace with the steps displayed on the video; this is an issue with CVM that is acknowledged in the literature (Mechling, Ayres, Bryant et al., 2014; Mechling, Ayres, Purrazella et al., 2014).

Continuous video prompting (CVP) was developed and analyzed to resolve the limitations noted with CVM. In CVP, the learner watches a clip of a step that automatically repeats until he or she completes the step (Cannella-Malone et al., 2015). A potential advantage of CVP over CVM for the student with ASD and/or ID is that only the step the learners are working on at any given time plays in a loop until the task is completed (Cannella-Malone et al., 2015). Cannella-Malone et al. (2015) studied the effectiveness of CVP on the acquisition of three DLS with one individual with ASD and ID. The targeted activities included washing a table, washing dishes, and cleaning 
windows. A video clip, with voice-over narration describing the step, was presented at the beginning of each activity; error correction was used, as needed. The results indicated that the approach was successful; however, there were noted issues with fading the strategy following intervention (Cannella-Malone et al., 2015). According to Cannella Malone et al., (2015), this study adds to the literature supporting the use of VP, while suggesting that CVP with error correction is also effective. Unlike previous studies implementing CVM, the participant in this study did not ask the researchers to stop or slow the video clips.

Notwithstanding this success, there are several limitations. One, there was only one participant; therefore, the external validity of the findings is unknown. Two, response prompts and error correction strategies were used as part of the CVP intervention. Thus, the variable, or combination of variables, responsible for skill acquisition are unknown. Three, the researchers did not count the number of video loop cycles needed for the participant to complete the steps of the task. This makes it difficult to determine the number of video loops needed to evoke participant behavior. Indeed, if just one video loop was viewed, this strategy would merely be VP instead of the variation, CVP. These limitations present opportunities and needs for further research.

\section{Purpose of the Study}

The purpose of this research is to narrow the gap in the literature regarding the use of CVP with children with ASD. Since the study uses CVP as the intervention, it is grounded in the work of Bandura (1977) on learning, and specifically, observational learning. A search within the current literature revealed only two studies addressing the effectiveness of CVM on teaching DLS to those with mild to moderate ID and/or ASD 
(Mechling, Ayres, Bryant et al., 2014; Mechling, Ayres, Purrazzella et al., 2014). Although these studies demonstrated positive outcomes with the use of CVM, this method may be less effective when used with individuals with moderate to severe ID and/or ASD, or when the targeted tasks are lengthy, thus paralleling issues known with traditional VM (Banda et al., 2011). Moreover, there is a paucity of research on the newest VBI strategy, CVP. The only research on this strategy was limited to one participant, and the use of error correction precludes others from determining the intervention components responsible for behavior change. Thus, the purpose of the current study was to examine the effectiveness of using CVP in isolation while recording the number of video loop cycles needed to evoke behavior. Results of this study could narrow the gap in the literature, as well as expand the knowledge of the effectiveness of CVP when working with children with ASD.

\section{Research Questions}

The following research questions guided this study.

1. Is CVP an effective strategy to teach DLS to children with ASD (ages 11-14 years) without the use of additional response prompts?

2. If improvements in learning the DLS are observed, to what extent will the skills maintain once the intervention is removed (i.e., weekly interval for three weeks) following the conclusion of CVP?

3. How many video segment loops need to be played for the participants to learn each step of the selected task? 


\section{CHAPTER III: METHODOLOGY}

The present study examined the effectiveness of continuous video prompting (CVP) on teaching children with Autism Spectrum Disorders (ASD) daily living skills (DLS). Chapter III provides information on the study's participants, setting, materials, independent and dependent variables, data collection systems, experimental design, procedures, data analysis, and social validity.

\section{Participant Information}

The study included four participants. Participants were middle school students enrolled in a private school in the southeast region of the United States. Four participants who consented were selected by the researcher following their teachers' nominations. To select study participants, the researcher adhered to the following processes. First, the researcher obtained approval from the school for the study to be conducted at that site. Second, the researcher submitted the school's approval with the Institutional Review Board (IRB) application to the FIU IRB. Third, once permission from FIU's IRB was obtained, the researcher met the principal and teachers of the selected private school to inform them of the details of the study. The information about the study included describing the purpose of the study and the participants' inclusion criteria. Fourth, the researcher provided an informational flyer to the teachers about the study, approved by FIU's IRB, to distribute to potential participants' parents or their legal guardians. Fifth, if the parents indicated interest in having their child participate in the study, then the parents were informed to contact the researcher to set up a meeting. Sixth, the researcher obtained written consent from the participants' parents for their children to participate in the study. Finally, the researcher asked the potential participants to provide written assent 
or verbal consent depending on the participants' ability. Once all these steps were followed, the researcher recruited four participants.

The participants' ages in this study ranged from 11- to 14-years old. Participants were selected on the basis of the following criteria: (a) participants had a diagnosis with ASD, (b) the participants were experiencing difficulty in DLS as stated in parental or teacher reports, (c) the participants had vision and hearing within the normal range with or without correction, (d) the participants were able to attend to and watch a video clip for at least one minute, (e) the participants had the ability to follow one- to two-step directions in English, and (f) the participants were able to imitate one- to two-step gross and fine motor movements. These skills were essential for the participants not only to participate in the study, but also to potentially benefit from the intervention. The aforementioned information was obtained via discussions with parents and teachers, as well as direct observation by the researcher while completing the Childhood Autism Rating Scale-Second Edition (CARS-2; Schopler, Van Bourgondien, Wellman, \& Love, 2010).

\section{Participant Characteristics}

All names used herein are pseudonyms for the study subjects. Rob was a 12-yearold, Hispanic boy. He had a diagnosis of ASD. Rob's overall CARS-2 score was 37.5, which indicated that he experienced severe symptoms of ASD. He had normal vision and hearing that was unaided. Rob could attend to a video for at least one minute, he could imitate one- to two-step gross and fine motor movements, he could make some requests vocally or by pointing to items, he could label items, and he could follow one- to twostep directions in English. 
Allen was a 12-year-old, Hispanic boy with a diagnosis of ASD. His overall CARS-2 score was 33.5, signifying that he experienced mild to moderate symptoms of ASD. His hearing and vision were reported to be at normal levels, and these were unaided. He could attend to videos for at least one minute. Additionally, Allen emitted echolalia, but he was able to make vocal requests, he could label items, and he could answer simple questions. Finally, he was able to imitate one- to two-step gross motor and fine motor movements, as well as follow one- to two-directions.

Samuel was a 13-year-old, Hispanic boy. His CARS-2 score was 44.5, and this score suggests that he experienced severe symptoms of ASD. Samuel had normal hearing and vision abilities that were unaided. He, too, could attend to videos for at least 1 minute. Samuel was able to imitate one-to two-step gross motor movements. Moreover, he could emit some vocal requests, and he could follow one-to two-step directions in English.

Ralph was an eleven-year-old boy of Hispanic heritage. He had a diagnosis of ASD, and his CARS-2 score was 43 indicating severe symptoms of ASD. He experienced normal vision and hearing without correction. Like the other participants, Ralph could watch a video for at least 1 minute, and he could imitate 1- to 2-step directions. Although he attempted to speak, it was difficult for others to understand him. He used a picture book to communicate. His teachers used pictures paired with their instructions to communicate to him, and Ralph could follow one-to two-step directions. Finally, it was reported that Ralph was quite resistant to changes in his routine; it was also reported that he would emit problem behavior. 


\section{Setting}

The setting for the study was in a private school located in the southeast region of the United States. Sessions transpired during school hours according to pre-baseline observations conducted by the researcher. All sessions took place in a spare room in the school measuring $5 \times 6 \mathrm{~m}$. The room was a standard classroom with one window and two doors. One door opened to the inside of the school and the other one opened to the outside. The room contained a square table in the middle, four chairs positioned around the table, and four high chairs in the corner of the classroom. Also, there was a small white board with greens decoration around the board. There were no other students in the classroom during sessions.

\section{Materials}

The materials the researcher used in the present study included the approved IRB forms. These forms consisted of the (a) parental consent form, (b) participant assent or verbal consent forms, (c) data collection forms, (d) inter-observer agreement forms, (e) treatment fidelity forms, and (f) social validity forms. Materials also included (a) technology (i.e., Apple iPad), (b) selected reinforcers, (c) three different colored papers (measuring 8.5”x11”), (d) three plastic baskets (measuring 3”x 4.75”x9.25”), (e) one legal-size wire desk tray (measuring 5"x11.75"x16.37”), (f) one clean seal envelope (measuring 6"x9"), and (g) a waste basket. The researcher provided all the materials needed for the study.

IRB approval forms. Approval to conduct the study was obtained from FIU's IRB before starting the study. The researcher followed FIU's IRB's approval for recruiting, consenting, and assenting participants. The IRB application demanded a full 
description and detailed information related to the study in order to protect the rights of the participants. The researcher met all requirements needed to obtain approval. The original IRB number was IRB-18-0405, and the amended IRB number was IRB-18-0405AM01.

Parent consent form. The parents of each participant were provided with a parent consent form that included all information required by the IRB. The purpose of the parental consent was to obtain written approval for the child's participation in the study. The form explained the purpose of the study, the process of the study, the time the study was taking place, benefits and risks of participating in the study, confidentiality, participant rights (participants were not penalized for quitting the study), and parents' signatures.

Adult participant consent form (teachers). The researcher obtained written consent that included all IRB required information from the participants' teachers to complete a social validity survey.

Child participant assent form and verbal consent form. Participants were either not able to read or were not able to comprehend language on a written assent form. Therefore, following the FIU IRB approved protocol, the researcher read the approved child verbal consent form to the participants. Each child provided his verbal consent to participate in the study.

Dependent variable data forms. The goal of the data collection form was to record the effectiveness of CVP and the number of video loops that the participant watched before correctly completing a step. There was a data collection form to measure 
the effectiveness of CVP on targeted tasks and how many loops the participants were watching to perform the targeted task correctly (see Appendix A \& B).

The data collection form included session information (e.g., participant's ID number, date of session, time of the session, the session number, session condition) and participant performance information (e.g., participant's response code, number of video loops viewed, and the percentage of correct and incorrect responses).

Interobserver agreement and treatment fidelity forms. The interobserver agreement (IOA) form was completed by the researcher and a second trained observer. There were two data collection forms to measure IOA: one form to assess baseline and maintenance (see Appendix C) and another form to assess the CVP intervention (see Appendix D). The IOA was defined as an evaluation of the reliability of data collected (Gast, 2010; Horner et al., 2005; Richards, Taylor, \& Ramasamy, 2014). Both the researcher and the second observer used the same data forms to record the participants' responses. Then, both of them calculated their agreeing and disagreeing responses by transferring their observational responses to the IOA data form.

Treatment fidelity (TF) was examined during all conditions of the study to measure the extent that the study's protocol was followed and implemented as designed. When researchers adhere to the study's protocol, the internal validity of the study is increased (Gast, 2010; Richards et al., 2014). There were two data collection forms to measure TF: one form to assess baseline and maintenance (see Appendix E) and another form to assess the CVP intervention (see Appendix F). These forms included information about the participant's ID number, data collector, date of sessions, time of sessions, and number of sessions. The planned procedures for targeting DLS were listed sequentially 
on the forms. A plus (+) was scored for correct applications of the study's procedures, a minus (-) was scored for incorrect applications of the study's procedures, or a not applicable (NA) was scored if a procedure was not required given a participant's response.

Social validity survey forms. Social validity is defined as the extent to which the target behavior, intervention procedures, and intervention results are socially important and acceptable (Wolf, 1978; Gast, 2010). The participants' survey included questions that were easy to understand (see Appendix G). Some of these questions included: (a) Did you like watching a video on the iPad? and (b) Did you think your daily living skills improved because you watched the video on the iPad? The researcher used a five-point Likert-type scale to rate the participants' responses. Participants had three rating options for responding: Yes, Maybe, No. Each answer choice corresponded to a visual icon to assist with comprehension (e.g., a smiling face).

Furthermore, the teacher's survey included questions on their perspective of the study, and participants' improvement of the DLS (see Appendix H). Some of the questions asked to the teachers included: (a) Did you notice an improvement in the participants' skills?, (b) Do you think the intervention was effective?, and (c) Do you think you will use CVP to teach DLS to other students? The researcher used a five-point Likert-type scale to rate the teacher's responses. Teachers had five rating choices to respond to: Strongly Agree, Agree, Neither, Disagree, Strongly Disagree.

Preference assessment data form. The aim of this data collection form was to record the potential preferences of participants and rank ordering those preferences. The data collection form included the participant ID number, the scoring instructions, the 
rankings of the preferred stimuli, and the trial-by-trial data on participants' selection. This data collection form was adapted from Cannella-Malone, Sabielny, Jimenez, \& Miller, 2013 (see Appendix I).

Technology and video recording. This research relied on technology as prompting for the participants. The researcher provided an iPad to the four participants. An iPad Air 2 was used as a self-prompting device. The iPad Air 2 is a portable media player and personal assistant with wireless capability developed and marketed by Apple, Inc. The iPad Air 2 has a rectangle shape, a glass screen (measuring 9.7” screen size), physical buttons, and a touchscreen. The video clips were played on the iPad using the built-in video player. Video clips for all four participants were developed using the same materials to be used by the participants during research sessions. All videos clips were filmed from a first-person perspective showing the arms and hands of someone else performing the task steps. The researcher recorded voice-over narration for each task step, and these were audible as each video clip played (i.e., "Put the paper in the envelope," or "Put the envelope in the basket"). These recorded videos were filmed using the Final Cut application on the iPad. Then, the final outcome of each video clip was uploaded into a photo's application for presentation. Each video clip depicting a task step repeated automatically for each of the five loops. Each video loop displayed the corresponding number for that video loop on the bottom left corner of the display. The task included 13 video clips with total duration of $6 \mathrm{~m}, 92 \mathrm{~s}$; individual video clips range from $21 \mathrm{~s}-1 \mathrm{~m}, 06 \mathrm{~s}$. 


\section{Independent and Dependent Variables}

The independent variables (IV) for this study was CVP and the number of video loops needed for participants to imitate the video and complete the task. The dependent variable (DV) for all participants was the total percentage of steps completed independently and correctly in each session across all conditions. In addition, the researcher counted how many video loops the participants watched for each step until correctly performing the task. For the purpose of the study, the targeted skill was collating different colors of papers, folding and stuffing the papers in an envelope, and then putting the envelope in a basket. The task analysis for the skill was as follows:

1. Put the green paper on the table,

2. Put the yellow paper on the table,

3. Put the blue paper on the table,

4. Pick up the papers and tap the table with the papers or straighten the papers on the table,

5. Fold the papers in half,

6. Pick up the envelope and open the envelope,

7. Put the papers in the envelope,

8. Put the envelope on the table with the papers in the envelope,

9. Take the paper covering the seal off the envelope

10. Throw away the small sealing paper,

11. Close the envelope with the papers in the envelope,

12. Press the envelope with the papers in the envelope, and

13. Put the envelope in the basket with the papers in the sealed envelope. 


\section{Data Collection}

The researcher collected data on (a) the number of task steps completed correctly, (b) the number of task steps completed incorrectly, (c) the number of video loops watched to complete the task, (c) IOA, (d) TF, and (e) social validity. When the participant began performing the steps during any viewing of one of the five video loops, a plus (+) was scored. If the participant responded within five seconds following the last video loop and performed the step accurately and independently within 30 seconds, it was also considered a correct response; a plus (+) was scored. When the participant did not perform the step within five seconds after viewing the last video loop (latency error), took more than 30 seconds to complete the step after viewing the last video loop (duration error), or performed the step incorrectly at any point while watching the video loops (topography error), it was considered an incorrect response, and a minus (-) was scored. The score of a session was determined by dividing the number of correct, independent steps by the total number of steps in the task analysis and multiplying by 100 (Ayres \& Ledford, 2014).

\section{Interobserver Agreement (IOA) and Treatment Fidelity Data Collection}

To strengthen the internal validity of the study, the reliability of the study, and the accuracy of collected data, a second observer and the researcher assessed participants' responses across sessions at the same time. Moreover, the second observer collected data independently from the researcher. Point-by-point IOA were collected whereby both observers had to agree on the data collected for each task step (Cooper, Herron, \& Heward, 2007). Then, they compared their data forms to calculate IOA. The collection of IOA data confirms that no observer drift occurs throughout the intervention, and that data 
are being collected according to the definitions and recording procedures established prior to the start of the study (Gast, 2010; Richards et al., 2014). The IOA data were collected during $47.4 \%$ of baseline sessions, 39.3\% of intervention sessions (including collecting IOA data on the corresponding video loops when the participants performed the behavior), and $33.3 \%$ of maintenance sessions. The IOA data should be collected during at least $25 \%$ across all sessions (Cooper et al., 2007). The IOA should be at least $80 \%$ agreement between both the researcher and the second observer at a minimum accuracy across all participants and conditions of the study (Gast, 2010; Richards et al., 2014). The formula for calculating IOA was the number of agreements divided by the number of agreements plus disagreements, and multiplied by 100 (Gast, 2010).

The independent observer evaluated the procedures implemented by the researcher during the sessions and across all participants (Gast, 2010). Treatment fidelity was collected by the independent observer during at least $30 \%$ across all conditions for each participant. The independent observer recorded data for TF during $47.4 \%$ of baseline sessions, $39.3 \%$ of intervention sessions, and $33.3 \%$ of maintenance sessions. The independent observer scored a plus (+) when a planned step was observed and score a minus (-) when a step was completed incorrectly. Not applicable (NA) was scored during those instances when a step could not be completed by the researcher due to participant responding. The TF was calculated by dividing the number of the steps correctly conducted by the total number of the steps and multiplying by 100 (Gast, 2010). The TF should be at least $90 \%$ in each session. If the result is less than $90 \%$, the researcher reviewed the proposed procedures to ensure that the implemented steps conformed to what was proposed before starting the study. 
The secondary observer was trained by the researcher and major professor before starting the study for both IOA and TF. The secondary observer was a doctoral student at FIU. To train the secondary observer and to calibrate the data collection methods, the major professor, along with the researcher and secondary observer, reviewed the data collection system and practiced collecting data in simulated research sessions with each other until at least $90 \%$ accuracy was achieved for three consecutive trails.

\section{Social Validity Data Collection}

The participants and the teachers involved in the study were given a survey to assess the social validity of the selected DLS and the effects of CVP at the end of the study. To measure social validity, the researcher met with the participants individually and after the study was completed to asked them questions about their experience.

The researcher met the teachers after the study to ask about their feedback regarding the use of CVP to address other target skills and their impressions of the study. Neither the participants nor the teachers were shown the results of the study prior to these meetings so that the results did not influence their feedback.

\section{Experimental Design and Rationale}

A single-subject design (SSD) was used in this study. According to Richards et al., (2014) and Bennett (2016), SSD is traditionally used in applied research, and is a quantitative method of scientific inquiry. It has been used by researchers for decades when conducting basic and applied research (Bennett, 2016). The term SSD refers to each participant serving as their control, which means each participant experiences each session of the study (Bennett, 2016; Cooper et al., 2007). Advantages of SSD are the ability to examine all the data on the participants' performance that lead the researcher to 
determine the effect of the IV on the DV, as well as the ability to determine if a functional relation exists (Bennett, 2016). Other advantages of SSD include the ability to examine the research question effectively among low-incidence, heterogeneous populations, such as individuals with ASD, its effectiveness for testing interventions aimed at changing performance, effective testing of interventions in applied settings including the classroom, and its cost-effectiveness (Bennett, 2016; Horner et al., 2005). The aim of using SSD is to determine a functional relation between the IV and the DV. When conducted properly, SSD enables researchers to demonstrate high levels of internal validity (Bennett, 2016). One weakness of SSD is limited external validity; very few participants are involved. Therefore, for resolution, replication of the original study is recommended (Bennett, 2016).

A multiple probe across participants design, which was used in the present study, is an example of an SSD that is proven to be beneficial in demonstrating experimental control (Horner \& Bear, 1978). The multiple probe across participants design was suited to analyze the relation between the IV in this study, which was the intervention, and the DV, which in the present study, was the DLS (Gast, 2010). The multiple probe across participants design involved three conditions: baseline, intervention using CVP, and maintenance. For baseline sessions, the researcher collected data on completed tasks for a given participant for a minimum of three to five data points until there was evidence of stability before introducing CVP. For the current study, stability was met when $80 \%$ of the data fell within $10 \%$ of the median for at least 3-5 sessions (Gast, 2010). Probe sessions were conducted with each participant in the baseline condition (Bennett, 2016). The first participant that received the CVP demonstrated stability in baseline, while the 
remaining participants stayed in the baseline probe condition. The baseline probes were conducted every three to five sessions or more if stability was not evident. Additionally, baseline probes were conducted at a minimum of one to three sessions immediately before CVP was applied with a participant. Once the first participant met the stability criteria during the CVP condition, CVP was introduced to the second participant having met the baseline stability requirement. The process of applying CVP was repeated for the third and fourth participants. Finally, maintenance data were collected using probe sessions for each participant for three weeks at weekly intervals following the conclusion of CVP.

A single subject design was used because it allows the researcher to constantly observe progress over the course of the study. The multiple probe design across participants permits the evaluation and demonstration of inter-subject replication, which can increase the internal and external validity of a study (Gast, 2010). The design does not require the removal and reintroduction of the intervention, thus avoiding the ethical concerns that arise when doing so. Moreover, the multiple probe designs are practical to measure the functional skills that are nonreversible once they are learned (Gast, 2010). Once participants had learned the skill targeted in the study, it is unlikely that they will stop performing the skill during the study. However, a threat to internal validity for the multiple probe design across participants is not collecting data continuously throughout the baseline condition for all participants. Yet, by collecting additional data, if instability was noticed, this threat can be mitigated. 


\section{Procedure}

Pre-baseline. During the pre-baseline, the researcher collected data including (a) interviewing teachers and/or caregivers, (b) observing participants to complete the Childhood Autism Rating Scale-2 (CARS-2; Schopler et al., 1988), and (c) conducting a preference assessment to determine potential reinforcers. The researcher identified the skill for all the participants. Additionally, the researcher and secondary observers practiced coding the data to calibrate the data collection systems.

During pre-baseline, the researcher observed the participants to mitigate participant reactivity (Gast, 2010). The researcher also confirmed participants' eligibility of ASD by asking their parents for a confirmation of ASD diagnosis; the parents were also asked about their children's age, if their children had difficulty with DSLs, vision, hearing, and if their children can watch a video-clip for at least 1 minute. Also, the parents were asked if their children could follow one- to two-step directions in English. Finally, the parents were asked about their child's fine motor skills. The researcher met with the participants' teachers to ascertain the participants needs. After several observations, the researcher observed the students to complete the CARS-2 assessment; the researcher also interviewed teachers to complete this assessment.

The researcher conducted a multiple stimulus preference assessment without replacement to identify potential reinforcers for each participant for use during the intervention (Carr, Nicolson, \& Higbee 2000). During the multiple stimulus preference assessment, the researcher placed a linear collection of five items (i.e., cup, car, stickers, ball, and bubbles) on a table in front of each participant. The participant was verbally instructed to select one item. The researcher repeated the directions no more than twice 
for the participant to select an item. After an item was selected, the researcher gave $10 \mathrm{~s}$ of access to the item (e.g., consume it for a drink or play with it for toys) before removing it from the participant. If the participant tried to select two items at once, the researcher prevented that and gave the participant verbal instructions to select one item (Carr et al., 2000). After an item had been selected, the researcher repositioned the rest of items and without the inclusion of the item previously selected. The process of applying a multiple stimulus preference assessment was repeated five times until a pattern of preference emerged. For scoring, the first selected item was given one point, the second item chosen was given two points, the third item selected was given three points, the fourth item selected was given four points, and the fifth item taken was given five points. The scores for each item were totaled at the end of five sessions, and items that received the lowest and second lowest scores were used as preferred items for the participants (CannellaMalone et al., 2013; Carr et al., 2000).

General procedure. The following processes were applied during all conditions across all sessions of the study. The researcher brought each participant from his classroom to the assigned room for the study where all the sessions were conducted. The researchers sat the participant on the chair facing the table. The researcher placed all the materials for the task on the table in front of the participant. The envelope and the wire basket were placed on the right side of the participant, and three trays, with the paper in front of the trays, were placed directly in front of the participant. During the CVP sessions, the iPad was placed on the table on the left side of the participant. The researcher started every session by giving the instruction to complete the task (i.e., put the papers in the envelope and put the envelop in the basket). At the end of the session, 
the researcher returned each participant to their class and received confirmation from the teacher that the participant was returned. In the case that the teacher attended the sessions with the participant, the participant went to the class with their teacher after the session ended.

Baseline. The researcher worked with participants individually, and the fixedopportunity probe method was used to assess baseline (Alexander, Ayres, Shepley, Smith, \& Ledford, 2017). During the baseline, the researcher was near the participant with task materials prepared and placed in front of the participant. The researcher provided a verbal instruction to the participant to start the task (i.e., "Put the papers in the envelope, and put the envelope in the basket.”). No instructional prompting was provided; CVP was not applied to the participants. The researcher set a time for $2 \mathrm{~m}$ for the participant to complete the task. The $2 \mathrm{~m}$ time limit was derived from the normative data collected whereby the researcher and the major professor performed the task steps three times each; their average performance was $26 \mathrm{~s}$. The $26 \mathrm{~s}$ timeframe was rounded to $30 \mathrm{~s}$ and multiplied by four to obtain the total duration allowed for each participant to complete the task during baseline. Participants could perform the task steps in any order, and they could err without interruption from the researcher. If the participants did not emit any behaviors for 30s, the researcher asked the participant if they were finished. If the participant said "yes," the researcher ended the session. If the participant said they were not finished with the task, the researcher let them continue. The researcher thanked the participant at the end of the sessions.

Intervention. The researcher worked with participants individually. All of the condition materials were placed in front of the participant as described in the baseline 
condition. The intervention condition began by the researcher giving the instruction for the participant to begin (i.e., "Put the papers in the envelope, and put the envelope in the basket. But first, watch the video.”). Then, the researcher played each clip and stated, "Watch this. The video then played with voice-over narration. The video looped back to the beginning until the participant completed the task or five loops of the video played. If the participant completed the task step at any time while the video was playing during one of the five viewing loops, the researcher provided verbal praise (i.e., "Good job", or "That was great."), recorded the step as correct, and advance the video to the next task step. If the participant did the task step incorrectly at any time while the video was playing during one of the five loops, the researcher recorded the step as incorrect, asked the participant to turn around, completed that step for the participant, advanced the video to the next step of the task, and asked the participant to turn around to view the next clip. The procedure was implemented to avoid a live modeling prompt and to set up the conditions for the next task step. If after the fifth video loop played, participants were given $5 \mathrm{~s}$ to initiate the step and $30 \mathrm{~s}$ to complete the step. If the participant performed the step within $5 \mathrm{~s}$ and completed the step correctly and independently within $30 \mathrm{~s}$, the researcher provided verbal praise, recorded the behavior as correct, and advanced the video to the next step.

If the participant did not start their response within $5 \mathrm{~s}$ (latency error), or completed the step within $30 \mathrm{~s}$ of the fifth loop of the video prompt (duration error), the researcher asked the participant to turn around, completed that step for the participant, advanced the video to the next step of the task, and asked the participant to turn around to view the next video. If the participant committed a topography error (emitted the wrong 
behavior) during the video playback during any of the five loops or after the fifth loop, the researcher asked the participant to turn around, completed that step for the participant, advanced the video to the next step of the task, and asked the participant to turn around to view the next video. The aforementioned CVP procedures continued until all task steps had been attempted or completed. Finally, the preferred stimuli determined during the preference assessment were given to a participant when he emitted 11 out of 13 steps correct.

Maintenance. Maintenance conditions were identical to the baseline conditions in that the participants were not watching a video on the targeted task or had any interaction with the researcher. The researcher was in the room collecting data on the targeted skill during the maintenance sessions. Participants were given $2 \mathrm{~m}$ to complete the task, and their performance within the $2 \mathrm{~m}$ was recorded and graphed. However, the researcher did not interrupt the participants if they continued working on the task beyond the $2 \mathrm{~m}$ time limit. (Note that these data that were collected beyond the $2 \mathrm{~m}$ time limit were recorded and graphed using a different symbol [see Results section for details]). Maintenance sessions started one week after the CVP was completed for each participant, and these sessions were implemented weekly for three weeks.

Data analysis. The researcher collected data continually for each participant and plotted the data on line graphs using the computer software, Graph Pad Prism. The researcher observed each participant's display of skill separately. The researcher analyzed the level, trend, variability, immediacy of effect, the consistency of data by conducting a visual analysis of the data (Cooper et al., 2007; Richards et al., 2014). Furthermore, the researcher analyzed the means and ranges for each condition of the 
study. Finally, the researcher analyzed the degree of data overlap between the baseline and intervention conditions using Tau- $U$ (Parker, Vannest, Davis, \& Sauber, 2011). Tau$U$ is a nonparametric effect size index used to examine the degree of data overlap between adjacent $\mathrm{AB}$ phase contrasts. In the current study A represents baseline and $\mathrm{B}$ represents intervention. Scores from Tau- $U$ are interpreted as follows: questionable effectiveness $=0-0.65$, effective $=0.66-0.92$, and very effective $=0.93$ and above (Rakap, 2015). Tau- $U$ data were generated for each participant, and these data are reported. Additionally, an omnibus Tau- $U$ effect size score for all participants combined was examined.

Analysis of social validity. Social validity data were analyzed using responses on the survey completed by participants and teachers. Collected data were averaged across participants' responses and teachers' responses. Each group's responses were calculated and obtained as the mean with the range for each question. Two of the child participants had minimal verbal communication skills. Thus, they pointed to the corresponding answer selection while saying, "yes" to communicate their responses to the survey. The other two participants were more verbal in their responses to the questionnaire.

\section{Summary}

This study investigated the effectiveness of CVP to improve DLS of participants with ASD. Before starting the study, appropriate consent to participate in the study was obtained. This study investigated the effects of CVP on the improvement of DLS through using a multiple probe across participants design. There were three conditions used in this study including baseline, intervention, and maintenance. A visual analysis of data was conducted to determine any effect the independent variable had on the dependent variable 
(Gast, 2010). Moreover, the Tau- $U$ non-overlap index was used to determine the effect size for each participant and the overall study with participants' data combined. 


\section{CHAPTER IV: RESULTS}

This chapter presents the results of a study that examined the use of continuous video prompting (CVP) on performing a daily living skill (DLS) among four middle school students with autism spectrum disorder (ASD). A multiple probe across participants design was implemented, and there were three conditions used in this study: (a) baseline, (b) intervention, and (c) maintenance. The independent variables were CVP and the number of video loops needed for viewing for participants to imitate the video and complete the task. The dependent variable was the total percentage of steps completed independently and correctly in each session across all conditions. This chapter details the results of the IOA data, TF data, an analysis of the results of the study, and an analysis of the social validity data collected from the participants and teachers.

\section{Interobserver Agreement}

The researcher and the second observer collected point-by-point interobserver agreement (IOA) data (Cooper et al., 2007). The IOA data were calculated by dividing the number of agreements by the number of agreements plus disagreements and multiplying by 100 . The IOA data for the entire study were collected during $40.7 \%$ of the sessions, and it equaled 99.7\% (range $=92.3-100 \%)$. Baseline IOA data were collected for $47.4 \%$ of the sessions and equaled $100 \%$ (range $=100-100 \%)$. During intervention, IOA data were collected for $39.3 \%$ of the sessions and equaled $100 \%$ (range $=100-$ $100 \%$ ), and IOA were collected for the number of video loops participants needed for $39.3 \%$ of the sessions and equaled $85.9 \%$ (range $=72.7-100 \%$ ). Maintenance IOA data were collected for $33.3 \%$ of the sessions, and equaled $98.1 \%$ (range $=92.3-100 \%)$. 


\section{Treatment Fidelity}

The treatment fidelity (TF) data were collected by second observer for $40.7 \%$ of the sessions. Total TF across all conditions and participants equaled 100\% (range $=100$ $100 \%)$. TF data were collected for $47.4 \%$ of the sessions during baseline and equaled $100 \%($ range $=100-100 \%)$. During intervention, TF data were collected for $39.3 \%$ of the sessions and equaled 100\% (range $=100-100 \%)$. Finally, TF data were collected for $33.3 \%$ of the sessions during maintenance and equaled $100 \%$ (range $=100-100 \%)$. The TF data were calculated by dividing the number of observed researcher behaviors by the number of planned researcher behaviors and multiplying by 100 (Gast, 2010).

\section{Results for Research Questions One and Two}

Research question one was: Is CVP an effective strategy to teach DLS to children with ASD (ages 11-14 years) without the use of additional response prompts? Research question two was: If improvements in learning the DLS are observed, to what extent will the skills maintain once the intervention is removed (i.e., weekly intervals for three weeks) following the conclusion of CVP? Overall, participants increased their performance of the selected task during the CVP intervention, with two participants maintaining higher levels of performing the skill when comparing baseline to maintenance sessions. For each participant, there were differences between baseline and intervention, and for the four participants the differences were substantial. The omnibus Tau- $U$ score was 0.99 , and this suggest that the intervention was very effective (Rakap, 2015). Figure 1 displays participants' performing the DLS during the conditions of the study. The number of steps correct is presented on the y-axis and sessions are presented on the x-axis. The closed circles represent participants' ability to complete the DLS, and 
the open circles represent participants' performance during maintenance when allowed to work beyond the $2 \mathrm{~m}$ timeframe (see Figure 1). 
Figure 1. Number of steps correct in the performance of the DLS. Closed circles represent participants' ability to complete the DLS, and the open circles represent participants' performance during maintenance when allowed to work beyond the $2 \mathrm{~m}$ timeframe.

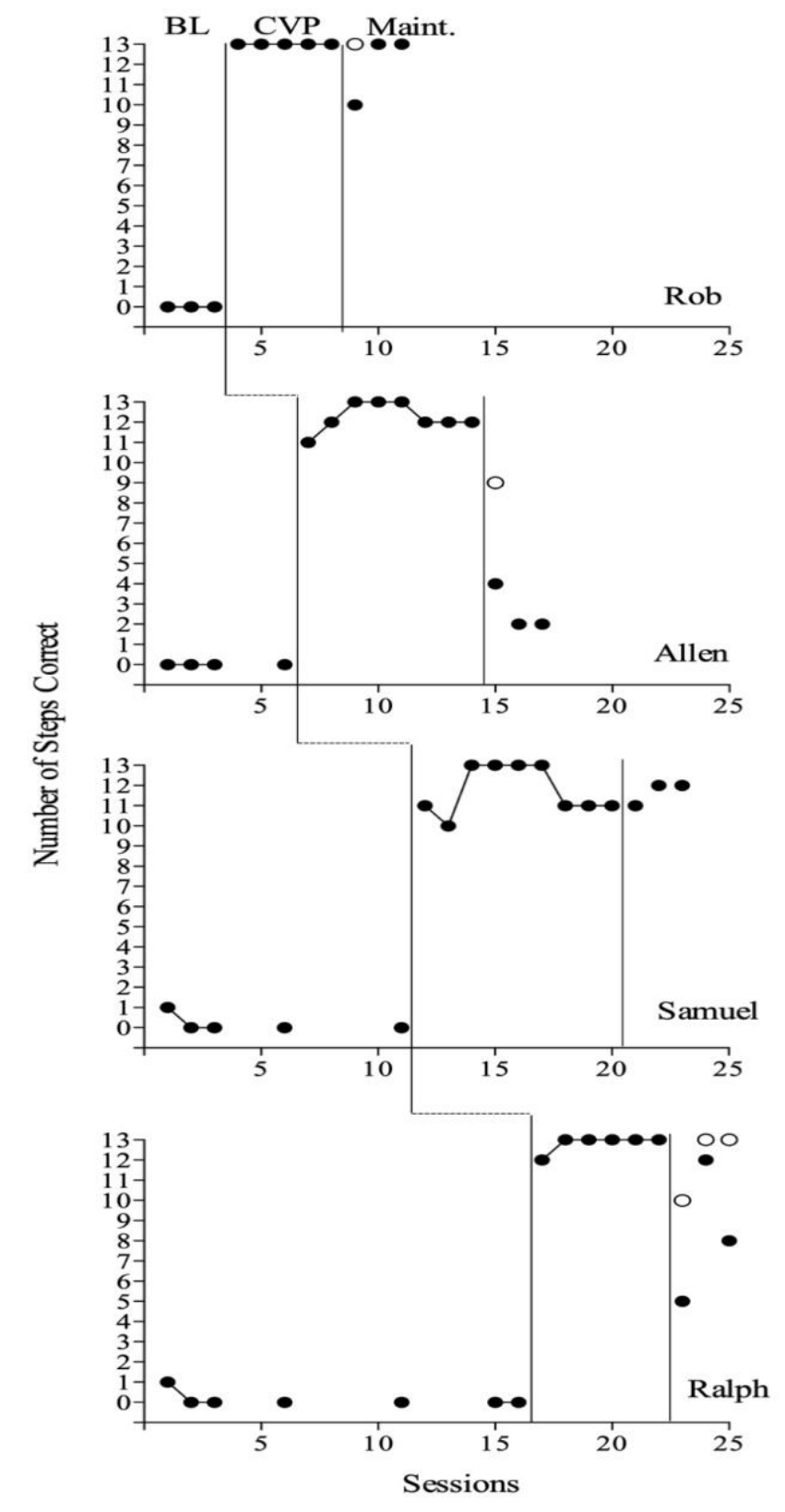




\title{
Rob
}

Rob was the first participant to receive the intervention. During baseline, his mean of performing the skill was zero correct steps (range $=0-0$ ). There was no variability, and a zero-celerating trend was present.

During CVP, his mean of performing the skill was 13 correct steps (range $=13$ 13 correct steps). Rob's data path during CVP was also stable with a zero-celerating trend. All five intervention sessions were 100\%. The immediacy of effect for Rob was strong (i.e., comparing the last data point in baseline to the first data point in CVP), with the final baseline data point being zero correct steps performing the task and the first intervention data point being 13 correct steps performing the skill. There was no overlap between baseline probes and the CVP data path. The Tau- $U$ score for Rob's AB phase contrast was 1.00 representing a very effective intervention effect (Rakap, 2015).

The average of performing the task during maintenance was 12 correct steps (range $=10-13$ correct steps). (Note that for maintenance session number one, Rob scored 10 out of 13 within two minutes. However, he was allowed to work beyond two minutes, and he actually scored 13 out of 13 steps correct.) Additionally, there was an ascending trend among these data points with slight variability (for the data collected within the $2 \mathrm{~m}$ time limit). Finally, there was no overlap between maintenance and baseline probes.

\begin{abstract}
Allen
Allen was the second participant to receive the intervention. During baseline, he completed zero steps correctly (range $=0-0$ correct steps). The baseline data path was stable with a zero-celerating trend, and there was no variability.
\end{abstract}


His mean performing the task steps during intervention was 12.3 (range $=11-13$ correct steps). According to the stability envelope using $80 \%$ of the data falling within $10 \%$ of the median (Gast, 2010), Allen's overall data path during intervention was stable. Moreover, his last three data points were stable at 12 correct steps with a zero-celerating trend. The immediacy of effect for Allen was strong, as he jumped from zero correct steps to 11 correct steps from the final baseline probe to the first CVP session, respectively. There was no overlap between the baseline probes and the CVP data path. The Tau- $U$ score for Allen's AB phase contrast was 1.00, and this suggests a very effective intervention effect (Rakap, 2015).

His average of performing the task steps during maintenance was 2.7 (range $=2-4$ correct steps). (Note that for maintenance session number one, Allen scored 4 out of 13 within 2 minutes. However, he was allowed to work beyond 2 minutes, and he actually scored 9 out of 13 steps correct.). There was a level change, indicating his performance of the task decreased after CVP was removed. Also, there was a descending trend during this maintenance condition of the study with some variability.

\section{Samuel}

Samuel was the third participant to participate in the intervention. After two additional baseline probes, Samuel had stable baseline data. During baseline, his mean of performing the task steps completed correctly was 0.2 (range $=0-1$ correct steps). There was a descending trend in the overall baseline data, but the last several data points were stable with a zero-celerating trend.

With stability of the baseline data points, Samuel was able to receive the CVP intervention. His mean of performing task steps correctly during CVP was 11.8 (range = 
10-13 correct steps). According to the stability envelope using $80 \%$ of the data falling within $10 \%$ of the median (Gast, 2010), Samuel's overall data path during CVP was variable. However, the final three CVP sessions for Samuel was stable at 11 correct steps each session with a zero-celerating trend. The immediacy of effect for Samuel was similar to that of Allen in that his final baseline probe session was zero steps completed correctly and his first CVP session was 11 correct steps. There was no overlap between the baseline probes and the CVP data path. The Tau- $U$ score for Samuel's AB phase contrast was 1.00, and this indicates a very effective intervention effect (Rakap, 2015).

There was also no overlap between maintenance and baseline probes. The average of performing the task steps correctly during maintenance was 11.7 (range $=11-12$ correct steps). There was an ascending trend during this condition with slight variability of the maintenance data points.

\section{Ralph}

Ralph was the fourth participant to receive the intervention. During his seven baseline sessions, his mean of performing the task steps was 0.1 correct $($ range $=0-1$

correct steps). There was a descending trend overall, but the last six baseline data points had a consistent pattern of stability with a zero-celerating trend.

Ralph received six CVP sessions, with the mean of performing the task steps correct at 12.8 (range $=12-13$ correct steps). There was an initial ascending trend with stability of the last five data points of this condition. The immediacy of effect for Ralph was strong, as he jumped from zero correct steps to 12 correct steps from the final baseline probe to the first CVP session, respectively. There was no overlap between the 
baseline probes and the CVP data paths. The Tau- $U$ score for Raph's AB phase contrast was 0.98 , indicating a very effective intervention (Rakap, 2015).

The average of performing the skill during maintenance was 8.3 correct steps (range $=5-12$ correct steps). (Note that Ralph scored 5, 12, and 8 steps correct for maintenance sessions $1,2, \& 3$, respectively within the 2 m time limit. However, when allowed to work beyond $2 \mathrm{~m}$, he scored 10, 13, and 13 for maintenance sessions 1, 2, and 3 , respectively.) When analyzing the data collected within the $2 \mathrm{~m}$ time limit, there was considerable variability during maintenance with no clear trend of the data during the three sessions.

\section{Results for Research Question Three}

Research question three was: How many video segment loops needed to be played for the participants to learn each step of the selected task? For each participant, there were differences in the average amount of video loops needed for viewing to complete the task steps, and there was variability of the video loops needed across the task steps and participants. When using traditional video prompting, participants are given the opportunity to view a video of a task step one time. By definition, CVP permits participants to view videos two or more times across the task steps; thus, the following will incorporate an analysis of when participants required multiple viewings of video clips across task steps. There were three different levels of variability demonstrated across these task steps. These levels included (a) no variability, (b) low variability where the range spans one level (e.g., one viewing to two viewings, four viewings to five viewings), (c) moderate variability where the range spans two levels (e.g., 0-2 viewings; 3-5 viewings), and (d) high variability where the range spans three levels or more (e.g., 
0-3 viewings; $1-4$ viewings). The box and whisker plot show the mean and the range of each step of the task analysis for each participant; the box shows the mean and the whiskers show the range (see Figure 2). The number of video loops needed for viewing is presented on the $y$-axis, and task analysis steps are presented on x-axis (see Figure 2). 
Figure 2. Mean and range of the video loops needed for viewing across participants and task steps.
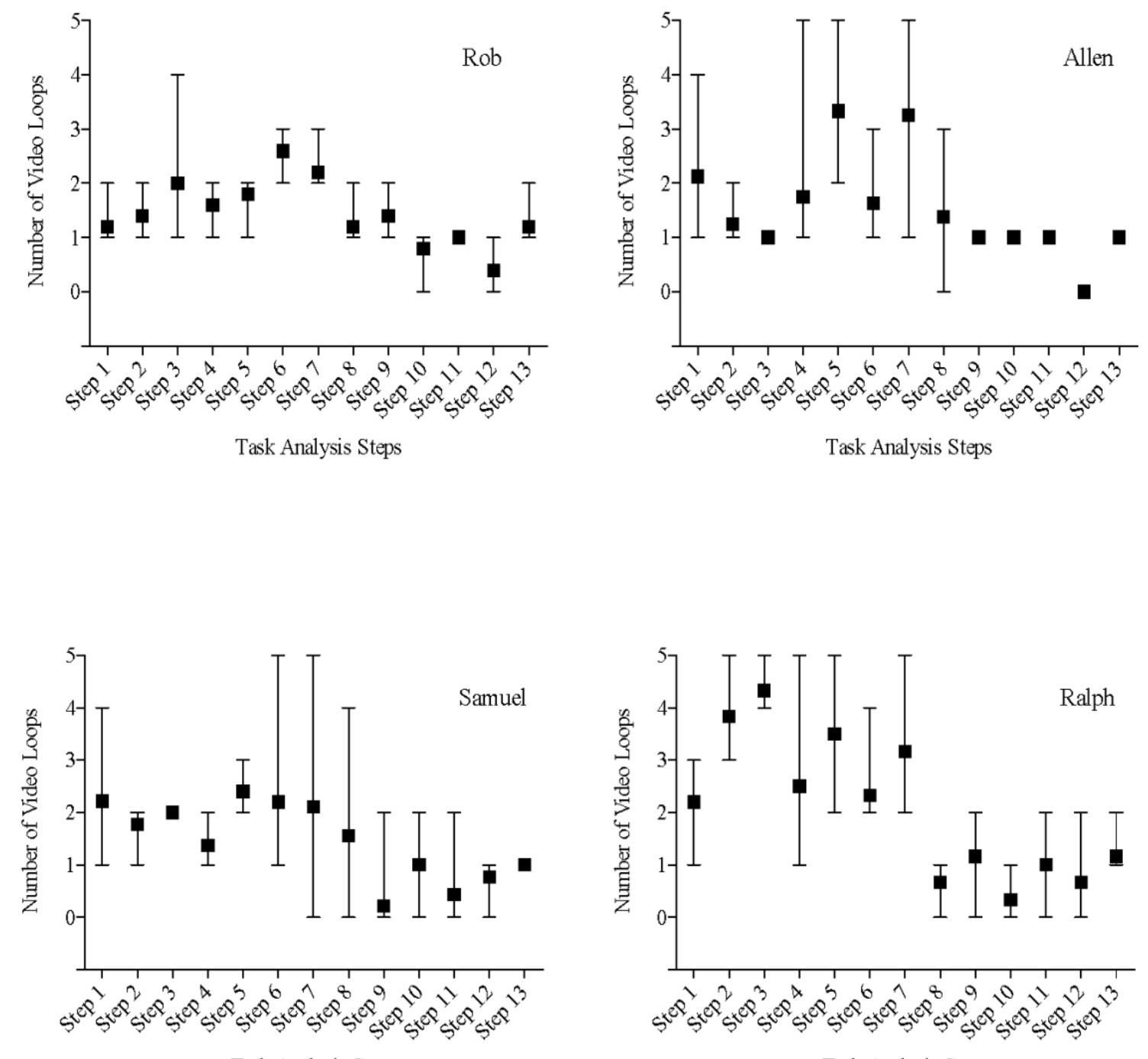

Task Analysis Steps

Task Analysis Steps 
Rob needed an average of two or more viewings of the video loops for steps three, six, and seven. Rob demonstrated no variability on step 11 . He displayed low variability on steps 1, 2, 4-10, and 12-13. On step three, his variability increased, and he required 1-4 viewings of the video while completing this step. (Note that he needed four viewings of the video for one session while only needing 1-2 viewings for the remaining sessions to complete step three.)

Allen needed an average of two or more viewings of the video loops for steps one, five, and seven. He had no variability on step three and steps 9-13. He had low variability on step 2 that required 1-2 viewings of the video to complete that step. Allen also demonstrated a moderate level of variability on step six. On steps one, four, five, seven, and eight, he had high levels of variability while viewing the videos when completing those steps.

Samuel needed an average of two or more viewings of the video loops for steps one, three, five, six, and seven. He demonstrated no variability on steps three and 13. However, Samuel showed low variability on steps two, four, five, and twelve. Moreover, he had moderate levels of variability on steps 9-11, with high levels of variability on the remaining steps.

Finally, Ralph needed an average of two or more viewings of the video loops for steps 1-7. Ralph exhibited low variability on steps three, eight, ten, and thirteen. On steps one, two, six, nine, eleven, and twelve, he had moderate levels of variability. When looking at steps four, five, and seven, Ralph demonstrated high levels of variability. 


\section{Social Validity}

Upon completion of the study the researcher met with the participants and teachers individually to ask them questions about their experiences. The results indicated that all four child participants answered the first question in the questionnaire with a happy face indicating agreement. Their overall data average for this question was 3 (range $=3-3)$. Their responses to the second question were showing agreement with a happy face. Their average score was 3 (range $=3-3$ ). In addition, they responded to the third question with agreement, and their average responses were 3 (range $=3-3$ ). Their responses to the fourth question in the questionnaire also showed agreement, and their average response was $3($ range $=3-3)$.

All four participants shared that they enjoyed viewing the videos through the iPad and the overall CVP intervention. Each participant indicated that he would use videos to learn other skills in the future. Moreover, after Rob's completion of the social validity form, he stated, "I like watching videos of things." In addition, Allen stated, "I like how the video shows the same things again." This statement might indicate that multiple viewings of the video helped him when he missed something while watching the video prompts. Thus, CVP could be potentially useful to Allen in learning skills as he was able to view video clips more than once.

Regarding the teachers' responses to the first question in the questionnaire, the results indicated that the overall average for this question was $4.5($ range $=4-5)$. Likewise, the overall average score for the second question was 4.5 (range $=4-5)$. As far as their responses to the third question, the average was 3 (range $=1-5$ ). Similarly, the 
responses for the fourth question averaged 3 (range $=1-5$ ). Finally, their responses for the fifth question averaged 3.75 (range $=1-5)$.

After the teachers completed the questionnaire, the researcher held a conversation with them and asked follow-up questions. Two teachers said the intervention was effective, and all four teachers said that CVP was acceptable to them given their classroom demands. The teachers who answered neither during the conversation suggested that perhaps it would be helpful to use CVP on Rob and Allen because they both liked the videos, but they wouldn't elaborate any further.

\section{Summary}

This study was conducted to examine the efficacy of using CVP to teach a DLS to individuals with ASD. This was done by using data taken during three different conditions of the study: baseline, intervention, and maintenance, with the dependent variable being task completion and the independent variables being CVP and the number of video loops viewed by participants to complete the steps. The results indicated that all of the participants substantially improved completion of the task when comparing the baseline to the intervention conditions. Also, two participants maintained their ability to complete the task steps during maintenance when comparing baseline to maintenance sessions, and when limiting participants' opportunity to complete the task steps to $2 \mathrm{~m}-$

which matched the baseline condition parameters. The results indicated that in this study, CVP did demonstrate efficacy in teaching a DLS to students with ASD. The responses of all the students to the social validity questionnaire administered to them at the conclusion of the maintenance phase indicated strong social validity. In conversations with these participants during this time, there was agreement on the intervention helping them learn 
the skill and a desire to use the intervention in the future to learn other skills. Regarding the social validity of the experiment with the teachers, there were varying levels of agreement on each of the points. 


\section{CHAPTER V: DISCUSSION}

This chapter discusses the results of this study, as well as implications of the findings and areas of future research. This study was concerned with the effectiveness of using continuous video prompting (CVP) on teaching a daily living skill (DLS) to children (aged 11-14 years) with autism spectrum disorder (ASD). In order to determine the effectiveness of CVP, three research questions were developed. Through each of the three questions, the researcher examined specific aspects of the effectiveness of the intervention: The first question examined general effectiveness, the second question was concerned with maintenance, and the third question was concerned with the number of video loop recordings of the task steps the participants needed to view in order to learn the skill. The following research questions guided this study.

1. Is CVP an effective strategy to teach a DLS to children with ASD (aged 11-14 years) without the use of additional response prompts?

2. If improvement in skill acquisition is observed, to what extent will the skills be maintained once the intervention is removed (i.e., weekly interval for three weeks following the conclusion of CVP)?

3. How many video segment loops need to be played for the participants to learn each step of the selected task?

The data were collected relative to each research question during each session conducted throughout the study. The study's design was a multiple probe across participants, single subject research design. There were three conditions in the study: baseline, intervention, and maintenance. To briefly summarize the results, all participants, to varying levels, exhibited improved performance on the DLS in the CVP 
condition (intervention) compared to their performance in the baseline condition. The findings from this study revealed a high omnibus Tau- $U$ score, representing that CVP was a very effective method for teaching the DLS to the study's participants (Rakap, 2015). After the removal of the intervention, two participants were able to maintain the selected task that was taught during the CVP condition when the time to complete the task was within 2 minutes. The other two participants did not maintain the task steps when considering the 2-minute time limit; however, when not accounting for that timeframe, one of these participants did maintain the skill.

\section{Findings for Research Questions One and Two}

Rob. Rob's results demonstrated the most significant effect of the intervention on teaching the selected task; this was true across the CVP and maintenance conditions. In the baseline condition, Rob could not complete any of the steps. In the intervention condition, Rob mastered all 13 steps of the selected task for all sessions. These results indicated that the effect was quite substantial for Rob, and the Tau- $U$ score for his data supports this finding.

In the maintenance condition, the researcher set the time for 2 minutes to complete the task, which replicated the baseline condition. During the first maintenance session, Rob was only able to complete 10 out of 13 steps of the selected task. While he could not complete the total number of steps for the selected task within 2 minutes, the number of the task steps he completed was significantly above his baseline of zero. However, when allowed to work beyond 2 minutes during the first maintenance session, Rob completed the entire task. On the second and third maintenance sessions, Rob was able to complete all 13 steps of the selected task within 2 minutes. This demonstrates a 
high degree to which the steps of the selected task learned through the use of CVP were maintained after the removal of the intervention.

Allen. In the baseline condition, Allen could not complete any of the steps of the selected task across all sessions. During the intervention sessions, Allen greatly improved in the number of steps of the selected task he could complete. When examining the data during the intervention condition, Allen was able to complete most, and in some sessions, all the steps of the selected task. During the first session in the intervention condition, Allen completed 11 steps of the selected task, and in the second session he completed 12 steps. During sessions 3-5, Allen was able to complete all 13 steps of the selected task. For intervention sessions 6-8, Allen's performance decreased to 12 steps during these last three sessions. He demonstrated the same error consistently in the last three sessions on step 5 (fold the papers in half). He could not fold the papers in half correctly, and there was no error correction for the purpose of the study. The researcher decided to advance him to the maintenance condition because he was stable for the last three sessions even though he was repeating the same error during the completion of these steps. The results indicated that the effect of CVP was considerable for Allen. Additional evidence of the strong intervention effect was revealed by examining his Tau- $U$ score, which indicated a very effective intervention (Rakap, 2015).

Over the three maintenance sessions, the researcher set the time for 2 minutes, as was done during the baseline condition. Allen's ability to complete the task fell drastically in the maintenance condition. In the first maintenance session, Allen was able to complete four of the 13 steps of the selected task within 2 minutes. When examining his data beyond the 2-minute time limit, he completed 9 out of 13 steps correctly during 
the first maintenance session. In maintenance sessions two and three, he only completed two of the steps correctly within the 2-minute time limit. While Allen did not maintain the selected task within the time frame, he did learn several of the steps, and this is evidenced by his completing nine out of the 13 steps beyond the two-minute time limit during the first session. The main implication related to this finding is that CVP may be a viable permanent prompt for this participant, and since it requires less human prompting, it could lead to greater independence when completing similar tasks. Notwithstanding this finding, if additional prompting or error correction was applied during the intervention, there may have been evidence of performing the selected task at higher levels leading to maintenance.

Samuel. While neither Rob nor Allen could do any of the steps during the baseline condition, Samuel, during the first baseline session, was able to complete one step. However, for the remainder of the baseline sessions, he could not complete any of the steps of the selected task. During the intervention condition, Samuel's performance improved significantly. During the first session in the intervention condition, Samuel completed 11 steps of the selected task, and in the second session he completed 10 steps. During sessions 3-6, Samuel was able to complete all 13 steps of the selected task. For intervention sessions 7-9, Samuel was able to complete 11 steps. Samuel demonstrated a seemingly consistent error pattern while performing steps five (fold the papers in half) and six (pick up the envelope and open it) during the last three sessions. He could not fold the papers in half correctly, and he could not open the envelope in a manner that would allow him to place the papers inside the envelope. The researcher decided to advance him to the maintenance condition because he was stable for the last three 
sessions while he consistently repeated the same errors during these sessions. Overall, the data collected on Samuel during this condition was variable, but the last three data points in the intervention were stable. These data in the intervention condition illustrate some variability in the effectiveness of the intervention on teaching the selected skill to Samuel. In order to gain more detailed insight into the effect of CVP, the researcher further examined the Tau- $U$ index related to Samuel's baseline data points and the CVP intervention data points, and the Tau- $U$ score for his data indicated a very effective intervention (Rakap, 2015).

During the maintenance condition, the researcher set the time for 2 minutes to complete the task steps, as was done with the other participants. Over the three sessions in the maintenance condition, the results for Samuel were promising; however, Samuel did not complete the 13 steps of the selected task in any of the sessions within 2 minutes. During maintenance session one, Samuel completed 11 of the 13 steps of the selected task. In maintenance sessions two and three, Samuel completed 12 out of the 13 steps, respectively. These results indicate that Samuel retained much, if not most, of what he learned during the intervention condition. There was an improvement of task step completion from the intervention condition to the maintenance condition.

During the final three sessions of the intervention condition, Samuel only completed 11 of the 13 steps of the selected task, and his data were stable. Samuel repeated this pattern during the first session of the maintenance condition, and he repeated the same errors for the same steps, which were step five (fold the papers in half) and step six (pick up the envelope and open it). Nonetheless, during the final two sessions of the maintenance condition, he was able to perform 12 of the 13 steps. He committed 
the same error on step six during the final two sessions of the maintenance condition. For the purpose of the study, there was no error correction during the CVP condition. If the error correction was applied with CVP, that might have improved Samuel's results in the maintenance condition. Cannella-Malone et al. (2015) found that their participant had learned the skills while they used both CVP and error correction. In the current study, during the CVP condition, Samuel was focused on watching the video clips looping; this focus may have translated into learning, which promoted maintenance. As was observed with Allen, CVP could serve as a permanent prompt that requires less human interaction for the learner, and it could foster greater independence from caregivers and professionals.

Ralph. During the first baseline session, Ralph completed one step of the selected task. In the remaining sessions of the baseline condition, Ralph could not complete any steps of the selected task. During the first intervention session, Ralph completed a total of 12 steps of the selected task. During the remaining five intervention sessions, Ralph completed all 13 steps. Ralph's intervention data were stable. His results were consistent during the intervention sessions, indicating the intervention was effective. Moreover, the Tau- $U$ score for his data supports this finding.

During the maintenance condition, Ralph's data were quite variable from sessionto-session when measured within the 2-minute time limit to complete the task steps. During the first session, Ralph performed five of the 13 steps. During the second maintenance session, Ralph completed 12 of the 13 steps needed to complete the selected task. In the final maintenance session, he performed eight of the 13 steps. When allowed to work on the selected task beyond the 2-minute time limit, he was able to complete 10 , 
13, and 13 steps for maintenance sessions one, two, and three, respectively. The results indicated the CVP was effective for Ralph regarding maintenance of the steps needed to complete the selected task, but only when examining his data beyond the 2-minute time limit.

\section{Implications for Research Questions One and Two}

The current study added to the existing literature on the effectiveness of using CVP to teach a DLS to individuals with ASD in several ways. Currently, there are not many published studies on using CVP to teach DLSs to individuals with ASD. In fact, the literature is limited to merely one study. Cannella-Malone et al. (2015) conducted a study using both CVP and error correction to teach three DLS to an individual with ASD and ID. While the intervention proved effective for teaching this individual, there were two limitations. The first limitation was that the sample size was limited to one participant. By contrast, in the current study, four individuals with ASD participated. While the current sample size is not large enough to be generalizable, it does illustrate that CVP could work for others with ASD. The second limitation of the Cannella-Malone et al. (2015) study was that their study used both CVP and error correction; it is unknown if the CVP was responsible for the improvement in the skills, if it was the error correction that was responsible for skill improvement, or if it was a combination of both interventions.

In the current study, CVP was the only method applied and there was no error correction or other prompting methods used other than CVP. Neither Allen nor Samuel could complete all 13 steps during the final three sessions of CVP, and both Allen and Samuel consistently repeated their errors in the same steps of the task. Adapting the Cannella-Malone et al. (2015) approach of using both CVP and another method of 
prompting as error correction could have increased the participants' abilities to work through all the steps of the task. These results illustrate that CVP could be effective in teaching DLS to children with ASD; however, some individuals might require additional prompting and additional research is recommended.

The literature on teaching multi-step tasks to individuals with developmental disabilities (DD) using VP has shown the approach to be an effective method (Bennett et al., 2013; Wu et al., 2016). In these studies, traditional VP was implemented, and some participants learned the skills gradually while others learned the skills rapidly. The study of Wu et al. (2016) used VP with error correction to teach a multi-step task to individuals with DD. The participants learned the skills gradually. They needed multiple sessions to acquire the skills when the VP was applied. Bennett et al. (2013) studied the effectiveness of using VP with and without voice over narration on teaching clerical skills to young children with ASD. Participants learned the skills rapidly. Participants met the criteria for acquisition of the skills after a few sessions of VP. Therefore, the literature is consistent regarding the effectiveness of VP for teaching individuals with ASD and DD. The literature is also consistent in demonstrating variation between the speed at which individuals learn the task. This is worth noting as Cannella-Malone et al. (2015) found that the participant with ASD and ID learned the skills gradually via CVP with error correction. The participant performed the skills with accuracy after multiple sessions of CVP. While in the current study, the individuals were able to learn the task steps rapidly during the intervention condition. The current study adds to the literature supporting the use of VP and CVP with error correction. The findings from the current study also suggests that using CVP in isolation is effective. However, more research is needed. 
VP and CVP utilize a task analysis to break down tasks into individual steps. Each step is then recorded as a video segment for both VP and CVP. The primary difference between the two interventions is in the presentation of the videos to the learners. In VP, a step's segment is played only one time; in CVP, a step's segment is played several times. CVP allows the learner to follow along as he or she works on the task steps. Cannella-Malone et al. (2015) found CVP to be effective for teaching a learner with ASD and ID, and their study provides precedent for using CVP for teaching individuals with ASD multi-step tasks. A possible benefit of CVP over VP for teaching individuals with ASD is the relationship between the repetition of the video playback and individuals' working memory. CVP allows implementers to play multiple video presentations of a step's segment, which could reduce the potential burden placed on individuals' working memory.

Working memory is related to how people store and process information (Kercood, Grskovic, Banda, \& Begeske, 2014). Working memory has been conceptualized as having the following components: (a) the phonological loop, which is linked to speech-based information; (b) the viso-spatial sketchpad, which stores information by its visual and spatial properties; and (c) the attention component, which allows a person to pay attention to something even when there are internal and external distractions (Kercood et al., 2014). All three components are required for processing material that can be applied to tasks such as organizing, learning, and cognitive flexibility (Kercood et al., 2014). Individuals with deficiencies in working memory often learn more slowly than those without deficiencies in working memory (Kercood et al., 2014). The attention component of working memory may be especially important when thinking 
about individuals with ASD. Individuals with ASD often experience problems with concentration. These problems are compounded when an individual must process multiple pieces of information at the same time, because their cognitive load is increased (Kercood et al., 2014). Research shows taxing cognitive load may further slow the learning for individuals with working memory problems.

This notion of cognitive load is aligned with existing research on working memory. In their research on working memory, Chen, Castro-Alonso, Paas, and Sweller (2018) found that prolonged mental effort can reduce working memory and adversely affect learning. There may be a possible advantage of CVP over VP for teaching multistep tasks to individuals with ASD. Individuals who experience working memory issues may have difficulty completing a step when exposed to only one demonstration of a video prompt. CVP may be less taxing on working memory because the video clip associated with each step repeats itself. Thus, if the learners miss something in a step, they could locate it again when the video clip repeats itself.

The second question of the current study focused on the maintenance of the selected task after removal of the CVP condition. Existing literature on CVP on teaching individuals with ASD is quite limited. In fact, the only existing literature examining the use of CVP to teach a DLS to a participant with ASD and ID is the research of CannellaMalone et al. (2015); in that study, there was no maintenance of the data recorded of the skills learned and retained by the participant. The current study differs from the existing literature because it examined the maintenance of what was learned in the intervention condition. The maintenance condition was introduced to determine the extent to which the participants retained what they learned through CVP when CVP was implemented in 
isolation. The maintenance data revealed that the effects of CVP could be extended after the CVP was removed. Therefore, the results are promising in indicating the degree to which the participants learned and retained the skill following the removal of CVP. Rob and Samuel did maintain much of what they learned while Allen and Ralph did not, as evidenced by their inability to perform the required tasks in the allotted time. However, when allowed more time beyond the 2-minute time limit, Ralph could complete 10 out of 13 steps for the first maintenance session and 13 out 13 steps for the remaining sessions.

\section{Findings for Research Question Three}

The third question asked how many video loop segments of each step were needed for participants to view to perform the DLS. The data regarding this research question shows variation in the number of video clip viewings the participants needed to perform the selected task steps. The variation was likely due to several factors. First, the variability of viewing the video clip could be due to the complexities of some steps. For instance, step four required participants to pick up the papers and either tap the table with the papers or straighten the papers on the table in order to be folded properly. Similarly, step six required participants to pick up the envelope and open it. However, some of the steps, such as steps $8-13$, were less complex and generally required less viewings of the video clips among the participants. These steps may have been easier to complete, but the researcher noted some variability among participants. Second, the variation in the number of video clips needed could also be due to some steps requiring a combination of fine motor skills and gross motor skills (e.g., steps 1-3, which required participants to pick up one piece of paper and place it on the table). Third, the variation in the number of video 
clips needed could be due to fine motor skills and visual perception skills required for a given step, such as steps five (fold the papers in half), six (pick up the envelope and open the envelope), and seven (put the papers in the envelope). Performing all of these steps successfully required adept fine motor skills and visual perception abilities.

\section{Implications for Research Question Three}

The current study adds to the existing literature on the use of CVP when teaching individuals with ASD. Bennett and Aljehany (2020) identified VP as useful for teaching chains of behaviors or multi-component tasks. With VP, a learner watches a video clip of one step of the task and then attempts that step before the next video clip is played. CVP is an extension of VP that allows learners to view a video clip of a task step more than once while trying to complete that step.

Cannella-Malone et al. (2015) examined the effects of CVP with an individual with ASD and ID. Although the results of that study showed that CVP was effective, Cannella-Malone et al. (2015) was not able to define the degree to which additional viewings of the video clips aided the participant with completing the tasks. Consequently, Cannella-Malone et al. (2015) were uncertain if CVP or VP was ultimately responsible for the participant's success in acquiring the task; this uncertainty was due to a lack of counting the additional video clip viewings needed by the participant to complete the steps. Thus, the current study adds to the literature because the researcher counted the number of video clips needed for viewing and determined that CVP — in isolation — was effective for teaching participants with ASD a daily living task.

One essential, and relevant, implication is the possibility of the individualization of instructional strategies that teachers, related professionals, and parents need to 
consider when using this strategy with students with ASD. Some students might need multiple viewings of the video clips during the early teaching sessions while learning new skills. Moreover, it is possible that the need for multiple viewings of a video could decrease to some degree over the sessions as the students acquire the skills. Alternatively, some students might need many viewings of the videos at specific points while preforming the skill, while other students might need continued viewing of video clips across time while completing the skill. These possibilities affect teachers and parents while making decisions based on the individual needs of students considering that students' abilities to acquire skills manifest in different learning patterns. Fortunately, this individualization is similar to what families and professionals experience in special education and related disciplines.

\section{Social Validity}

Social validity was important to this study for several reasons. Social validity measures whether the participants and their teachers believe the intervention to be socially important (Gast, 2010). Wolf (1978) identified three elements of social validity, and these included how individuals perceived the goals, procedures, and outcomes of interventions. For this current study, a questionnaire was given to participants and their teachers that addressed each of these parts of social validity.

The participants. The child social validity questionnaire was administered to each participant. The questionnaire contained four statements relating to social validity. Each statement was followed by three choices to indicate agreement or lack thereof. A response of "yes" was indicated by a happy face, a response of "maybe" was indicated by a face with a hand on its chin, and a response of "no" was indicated by a face with a 
frown. For each of the four questions, all of the participants responded in the affirmative. Thus, the participants all felt that the skill being learned was important, watching the videos helped them to improve their ability to learn the skill, that they would use videos in the future to learn other skills, and finally, that watching videos was fun. Moreover, two of the four participants were more verbal than the other two participants, and the researcher engaged them in conversation regarding the social validity of the study. Rob said that he enjoyed watching the videos, and Allen liked that the videos repeated what they showed. The other two participants were less verbal and did not engage much in conversation with the researcher. The two participants' comments and the overall agreement of the four participants on the questionnaire support the high social validity of this study.

The teachers. The results of the teacher social validity questionnaire illustrated that there was not a full agreement among the teachers regarding the social validity of the intervention. All of the teachers agreed the skill was important for the participants to learn, with two indicating it was very important. Moreover, all of the teachers agreed to varying degrees that the intervention was acceptable within the demands of the classroom. The agreement was divided regarding the effectiveness of the intervention, with two teachers strongly agreeing that the intervention was effective, and two teachers neither agreeing nor disagreeing with the effectiveness of the intervention. As stated in the previous chapter, not every teacher attended all of the sessions, and this could have influenced the responses regarding the usefulness and effectiveness of CVP for teaching a DLS. Additionally, the teachers' results were divided on agreement of whether they would use CVP to teach a DLS to other students: two teachers responded with strongly 
agreed, and two teachers indicated they neither agreed nor disagreed. The respondents indicated some agreement with the final statement on teacher satisfaction; two teachers strongly agreed, one teacher agreed, and one chose neither with the statement. The teachers' responses indicated their belief in a degree of social validity for the study, but not to the extent of the beliefs held by the child participants.

\section{Limitations and Future Research}

There are several limitations that should be addressed in future research. The first limitation is the sample size and resulting inability to generalize the findings beyond the current study. With only four participants, the results are not easily generalizable to the greater population of children with ASD. Thus, additional research is suggested to replicate this study with other children with ASD. Moreover, future research is needed on this topic among participants with other disabilities (e.g., intellectual disability).

Second, each participant had three maintenance sessions over a three-week period. It is unknown whether or not the participants could maintain the selected task over longer periods of time. Therefore, future researchers are encouraged to examine the maintenance potential of this intervention over a longer period of time.

The third limitation is the study environment itself. The physical environment of the study was not the regular classroom of the participants, but rather, the study was conducted in a vacant classroom. It is unknown if the results would have been different had the study taken place in the participants' actual classroom environment. Thus, future research should be conducted in the participants' actual classroom environment to determine if results are similar to the findings of this study. 
A fourth limitation is the participants' ages. This study's participants were all in a specific age group (11-14 years old). It is unknown if CVP is useful and effective in teaching DLS to individuals of other ages, and additional research with younger and older participants might clarify another area of external validity.

A fifth limitation is the participants were from the same cultural and linguistic background. The effects of CVP with participants from other cultural and linguistic backgrounds is unknown, and additional research might clarify another area of external validity.

The final limitation relates to how participants completed the task in relation to the number of video viewings it took to complete each step of the task. It is unknown, other than anecdotally, to what degree the participants viewed the number of video clip repetitions that played as they completed the steps. The researcher observed students attending to multiple viewings of the given steps; however, data on this particular behavior were not collected. It is possible that the video clips repeated multiple times without the participants always watching the video multiple times. That is, at times, participants may have required additional time to complete a step but did not need to view the videos more than once. Future researchers should consider measuring if students are watching the repetition of the video clips in order to complete the steps or if they simply need additional time to complete the steps. For some participants, the additional video viewings might be needed during early acquisition. For other individuals, it is possible that additional video viewings are needed across several, the majority, or all of the sessions. Additional researchers should examine this issue. 


\section{Summary}

ASD is a neurodevelopmental disorder that adversely affects socialcommunication skills among the individuals that experience this disability. In addition, individuals with ASD often exhibit difficulty in repetitive behaviors and interests. Some challenging behaviors associated with ASD could affect learning in a classroom environment.

Teaching individuals with ASD can be quite challenging due to the impairments and problem behaviors sometimes associated with the disability. One set of interventions that has been broadly used to teach a variety of skills and behaviors to individuals with DD, including ASD, is VBI (Banda et al., 2011). VBI includes several methods such as VM, CVM, VP, and CVP. While there are subtle differences among all of these approaches, they all use video to teach individuals with ASD. Video modeling is a technique wherein the learner watches a task from beginning to completion and uses it as a model to complete the task himself or herself. With VM, the video plays one time from the beginning to the end. CVM is similar to VM, in that it uses a video to demonstrate how to complete a task from start to finish, but unlike VM, the video loops over and over, for several times rather than ending after the first viewing. This allows learners with ASD to complete the task at their own pace because the video will loop continuously; the learners can see the step they are on and follow from there. Video prompting, on the other hand, divides a task into steps. Learners watch a step and then complete that step before moving onto the next video of the next step. As with VM, in VP, the step only plays one time. CVP is similar to VP in that it breaks down tasks into steps. However, CVP differs from VP in that the video displaying a given task step repeats multiple times, and this 
permits students to watch a given step multiple times as they work to complete that step. This may be beneficial for teaching individuals with ASD experiencing working memory issues. In addition, each type of VBI mentioned can be used independently of other interventions or in conjunction with other interventions, such as prompting and error correction.

The current study focused on using CVP in teaching a DLS to children with ASD aged 11 to 14 years. This study was concerned with three questions: (a) Is teaching individuals a DLS using CVP without additional prompts effective? (b) If CVP is effective, to what extent is the learning maintained? and (c) How many video segments are needed for viewing in order for participants to perform each step? In order to answer these questions, a single subject research design methodology was applied using four participants with ASD. Data were collected during three conditions: baseline, intervention, and maintenance. The DLS selected was to take three different color papers, sort them, place the papers in an envelope, seal the envelope, and place the envelope in a basket; this task involved a total of 13 steps.

The study's results were promising. The participants showed rapid improvement in skill development during the intervention, but there was variability in number of video clip loops needed for viewing. All participants improved in the intervention condition when compared to baseline; some participants also improved when comparing the maintenance condition to the baseline condition. The main implication from the results of this study is that CVP could be effective in teaching a DLS to children with ASD without the use of any other prompts. However, the results of this study are not definitive as 
future research must be conducted by replicating this study to determine if using CVP to teach children with ASD is truly effective in teaching DLSs. 


\section{REFERENCES}

Alexander, J.L., Ayres, K.M., Shepley, S.B., Smith, K.A., \& Ledford, J.R. (2017). Comparison of probe procedures in the assessment of chained tasks. The Psychological Record, 67(4), 547-557. DOI 10.1007/s40732-017-0257-9

American Psychological Association. (2013). Diagnostic and statistical manual of mental disorders (5th ed.). Washington, DC: American Psychological Association.

Ayres, K. M. \& Langone, J. (2005). Intervention and instruction with video for students with autism: A review of the literature. Education and Training in Developmental Disabilities, 40(2), 183-196.

Ayres, K. M., \& Ledford, J. R. (2014). Dependent Measures and Measurement Systems. In D. L. Gast and J. R. Ledford (Eds.). Single case research methodology: Applications in special education and behavioral sciences (2nd Ed.) (pp. 124153). New York, NY: Routledge.

Ayres, K. M., Lowrey, K. A., Douglas, K. H., \& Sievers, C. (2011). I can identify Saturn but I can't brush my teeth: What happens when the curricular focus for students with severe disabilities shifts. Education and Training in Autism and Developmental Disabilities, 46(1), 11-21.

Baio, J. (2012). Prevalence of autism spectrum disorders: Autism and developmental disabilities monitoring network, 14 sites, United States, 2008. Centers for Diseases Control and Prevention Morbidity and Mortality Weekly Report, 61, 119.

Banda, D. R., Dogoe, M. S., \& Matuszny, R. M. (2011). Review of video prompting studies with persons with developmental disabilities. Education and Training in Autism and Developmental Disabilities, 46(4),514-527.

Bandura, A. (1969). Social-learning theory of identificatory processes. In D. A. Goslin (Ed.), Handbook of socialization theory and research (pp. 213-262). Chicago: Rand McNally.

Bandura, A. (1977). Social learning theory. Englewood Cliffs, NJ: Prentice Hall.

Bandura, A. (1986). Social foundation of thought and action: A social cognitive theory. Englewood Cliffs, NJ: Prentice- Hall.

Barton, E., Lawrence, K., \& Deurloo, F. (2012). Individualizing interventions for young children with autism in preschool. Journal of Autism and Developmental Disorders, 42, 1205-1217. 
Batu, S., Ergenekon, Y., Erbas, D., \& Akmanoglu, N. (2004). Teaching pedestrian skills to individuals with developmental disabilities. Journal of Behavioral Education, 13, 147-164.

Bellini, S., \& Akullian, J. (2007). A meta-analysis of video modeling and video selfmodeling interventions for children and adolescents with Autism Spectrum Disorders. Exceptional Children, 73(3), 264-287.

Bennett, K. D. (2016). The utility of single-subject design research. International Journal of Adult Vocational Education and Technology, 7(2), 20-31.

Bennett, K.D., \& Aljehany, M.S. (2020). Video prompting. Volkmar (Ed.), Encyclopedia of Autism Spectrum Disorders. New York: Springer.

Bennett, K. D., Gutierrez, A., \& Honsberger, T., (2013). A comparison of video prompting with and without voice-over narration on the clerical skills of adolescents with autism. Research in Autism Spectrum Disorders, 7, 1273-1281.

Bennett, K. D., Gutierrez Jr, A., \& Loughrey, T. O. (2016). Comparison of screen sizes when using video prompting to teach adolescents with autism. Education and Training in Autism and Developmental Disabilities, 51(4), 379-390.

Blum-Dimaya, A., Reeve, S. A., Reeve, K. F., \& Hoch, H. (2010). Teaching children with Autism to play a video game using activity schedules and game-embedded simultaneous video modeling. Education and Treatment of Children, 33, 351-370.

Boutot, E., \& Myles, B. (2011). Autism spectrum disorders: Foundations, characteristics, and effective strategies (4th ed.). Boston, MA: Pearson.

Brown, L., Branston, M. B., Hamre-Nietupski, S., Pumpian, I., Certo, N., \& Gruenewald, L. (1979). A strategy for developing chronological-age-appropriate and functional curricular content for severely handicapped adolescents and young adults. Journal of Special Education, 13, 81-90.

Cannella-Malone, H. I., Sabielny, L. M., Jimenez, E. D., \& Miller, M. M. (2013). Pick one: Conducting preference assessments with students with significant disabilities. TEACHING Exceptional Children, 45(6), 16-23.

Cannella-Malone, H. I., Sabielny, L. M., Jimenez, E. D., Page, E. J., Miller, M., \& Miller, O. (2015). Use of continuous video prompting to teach a student with a significant disability. Journal of Developmental and Physical Disabilities, 27(6), 745-754.

Cannella-Malone, H., Sigafoos, J., O'Reilly, M., de la Cruz, B., Edrisinha, C., \& Lancioni, G. E. (2006). Comparing video prompting to video modeling for 
teaching daily living skills to six adults with developmental disabilities. Education and Training in Developmental Disabilities, 41(4), 344-356.

Cardon, T. A., Guimond, A., \& Smith-Treadwell, A. M. (2015). Video modeling and children with Autism Spectrum Disorder: A survey of caregiver perspectives. Education and Treatment of Children, 38(3), 403-419.

Cardon, T. A., \& Wilcox, M. J. (2011). Promoting imitation in young children with autism: A comparison of reciprocal imitation training and video modeling. Journal of Autism and Developmental Disorders, 41(5), 654-666.

Carnahan, C. R., Hume, K., Clarke, L., \& Borders, C. (2009). Using structured work systems to promote independence and engagement for students with autism spectrum disorders. Teaching Exceptional Children, 41(4), 6-14.

Carr, J. E., Nicolson, A. C., \& Higbee, T. S. (2000). Evaluation of a brief multiplestimulus preference assessment in a naturalistic context. Journal of Applied Behavior Analysis, 33(3), 353-357.

Centers for Disease Control and Prevention (2009). Prevalence of autism spectrum disorders-Autism and developmental disabilities monitoring network, United States, 2006. MMWR Surveillance Summary, 58(SS-10).

Centers for Disease Control and Prevention (2014). Autism Spectrum Disorders, Data and Statistics. Retrieved from http://www.cdc.gov/ncbddd/data.html.

Centers for Disease Control and Prevention (2020). Prevalence of autism spectrum disorder among children aged 8 years - autism and developmental disabilities monitoring network, 11 sites, United States 2016. Morbidity and Mortality Weekly Report, 69(4), 1-12.

Chen, O., Castro-Alonso, J. C., Paas, F., \& Sweller, J. (2018). Extending cognitive load theory to incorporate working memory resource depletion: Evidence from the spacing effect. Educational Psychology Review, 30(2), 483-501. https://doi.org/10.1007/s10648-017-9426-2.

Cooper, J. O., Heron, T. E., \& Heward, W. L. (2007). Applied behavior analysis (2nd ed.). Upper Saddle River, NJ: Prentice Hall.

Corbett, B. A. (2003). Video modeling: A window into the world of autism. The Behavior Analyst Today, 4(3), 367.

Cronin, M. E. (1996). Life skills curriculum for students with learning disabilities. Journal of Learning Disabilities, 29, 53-68. 
Dawson, G., Webb, S., Schellenberg, G. D., Dager, S., Friedman, S., Aylward, E., \& Richards, T. (2002). Defining the broader phenotype of autism: Genetic, brain, and behavioral perspectives. Development and Psychopathology, 14(3), 581-611. doi:10.1017/S0954579402003103

Deisher, T. A. \& Doan, N. V. (2015). Sociological environmental causes are insufficient to explain autism change points of incidence. Issues in Law \& Medicine, 30(1), 25-52.

Delano, M. E. (2007). Video modeling interventions for individuals with autism. Remedial and Special Education, 28(1), 33-42.

Dorwick, P.W., \& Jesdale, (1991). Practical guide to using video in the behavioral sciences.

New York: John Wiley \& Sons, Inc.

Dube, W. W., Farber, R. S., Mueller, M. R., Grant, E., Lorin, L., \& Deutsch, C.K., (2016). Stimulus over selectivity in autism, Down Syndrome, and typical development. American Journal on Intellectual and Developmental Disabilities, 121(3), 219-235.

Edrisinha, C., O’Reilly, M. F., Choi, H. T., Sigafoos, J., \& Lancioni, G. E. (2011). "Say cheese:" Teaching photography skills to adults with developmental disabilities. Research in Developmental Disabilities, 32, 636-642.

Esler, A. N., \& Ruble, L. A. (2015). DSM-5 diagnostic criteria for autism spectrum disorder with implications for school psychologists. International Journal of School \& Educational Psychology, 3(1), 1-15. doi: $10.1080 / 21683603.2014 .890148$

Flynn, L., \& Healy, O. (2012). A review of treatments for deficits in social skills and selfhelp skills in autism spectrum disorder. Research in Autism Spectrum Disorders, 6(1), 431-441.

Folstein, S., \& Rutter, M. (1977). Infantile autism: A genetic study of 21 twin pairs. Journal of Child psychology and Psychiatry, 18(4), 297-321.

Gardner, S., \& Wolfe, P. (2013). Use of video modeling and video prompting interventions for teaching daily living skills to individuals with autism spectrum disorders: A review. Research and Practice for Persons with Severe Disabilities, 38(2), 73-87.

Gardner, S., \& Wolfe, P. (2015). Teaching students with developmental disabilities daily living skills using point-of-view modeling plus video prompting with error 
correction. Focus on Autism and Other Developmental Disabilities, 30(4), 195207. doi: 1088357614547810

Gast, D. L. (2010). Single subject research methodology in behavioral sciences. New York, NY: Routledge.

Gies, M., \& Porretta, D. (2015). Video prompting and its application to physical activity settings for individuals with developmental disabilities, Palaestra, 29(4), 31-35.

Goodson, J., Sigafoos, J., O’Reilly, M., Cannella, H., \& Lancioni, G. (2007). Evaluation of a video-based error correction procedure for teaching a domestic skill to individuals with developmental disabilities. Research in Developmental Disabilities, 28(5), 458-467.

Hall, L. (2013). Autism spectrum disorders from theory to practice (2nd Ed). Upper Saddle River, New Jersey: Pearson Education, Inc.

Ham, H. S., Corley, M., Rajendran, G., Carletta, G., \& Johnson, S. (2007). Brief report: Imitation of meaningless gestures in individuals with Asperger Syndrome and high-functioning Autism. Journal of Autism and Developmental Disabilities, 38, $569-573$.

Hattier, M. A., \& Matson, J. L. (2012). An examination of the relationship between communication and socialization deficits in children with autism and PDD. Research in Autism Spectrum Disorders, 6(2), 871-880.

Heflin, L. J., \& Simpson, R. L. (1998). Interventions for children and youth with autism: Prudent choices in a world of exaggerated claims and empty promises. Part 1: Interventions and treatment options review. Focus on Autism and Other Developmental Disabilities, 13(19), 4-211.

Heimann, M., Nordqvist, E., Strid, K., Connant-Almrot, J., \& Tjus, T. (2016). Children with autism respond differently to spontaneous, elicited and deferred imitation. Journal of Intellectual Disability Research, 60(5), 491-501.

Hendricks, D. R., \& Wehman, P. (2009). Transition from school to adulthood for youth with autism spectrum disorders: Review and recommendations. Focus on Autism and Other Developmental Disabilities, 24(2), 77-88. doi:10.1177/1088357608329827

Hodgdon, L. Q. (1995). Solving social- behavioral problems through the use of visually supported communication. In K. A. Quill (Ed.), Teaching children with autism: Strategies to enhance communication and socialization (pp. 265-286). New York: Delmar. 
Hong, E. R., Ganz, J. B., Mason, R., Morin, K., Davis, J. L., Ninci, J., ... \& Gilliland, W. D. (2016). The effects of video modeling in teaching functional living skills to persons with ASD: A meta-analysis of single-case studies. Research in Developmental Disabilities, 57, 158-169.

Horner, R. D., \& Bear, D. M. (1978). Multiple probe technique: A variation on the multiple baseline. Journal of Applied Behavior Analysis, 11,189-196.

Horner, R. H., Carr, E. G., Halle, J., McGee, G., Odom, S., \& Wolery, M. (2005). The use of single-subject research to identify evidence-based practice in special education. Exceptional Children, 71(2),165-179.

Hume, K., Loftin, R., \& Lantz, J. (2009). Increasing independence in autism spectrum disorders: A review of three focused interventions. Journal of Autism and

Developmental Disorders, 39(9), 1329-1338. doi:10.1007/s10803-009-0751-2

Irwin, R.B. (1981). Training speech pathologists through microtherapy. Journal of Communication Disorders, 14, 93-103.

Jarvis, P., Holford, J., \& Griffin, C. (2003). The theory and language of learning (2nd ed.). Sterling, VA: Kogan Page.

Kanner, L. (1943). Autistic disturbances of affective contact. Nervous Child, 2, 217-250.

Kercood, S., Grskovic, J. A., Banda, D., \& Begeske, J. (2014). Working memory and autism: A review of literature. Research in Autism Spectrum Disorders, 8(10), 1316-1332.

Keen, D., Brannigan, K. L., \& Cuskelly, M. (2007). Toilet training for children with autism: The effects of video modeling. Journal of Developmental and Physical Disabilities, 19, 291-303.

Kellems, R. O., \& Morningstar, M. E. (2012). Using video modeling delivered through iPods to teach vocational tasks to young adults with autism spectrum disorders. Career Development and Transition for Exceptional Individuals, 35(3), 155-167.

Kelly, M. P., Leader, G., \& Reed, P. (2015). Stimulus over-selectivity and extinctioninduced recovery of performance as a product of intellectual impairment and autism severity. Journal of Autism and Developmental Disorders, 45(10), 30983106.

Kim, Y. S., \& Leventhal, B. L. (2015). Genetic epidemiology and insights into interactive genetic and environmental effects in autism spectrum disorders. Biological Psychiatry, 77(1), 66-74. doi: 10.1016/j.biopsych.2014.11.001. 
Kleeberger, V., \& Mirenda, P. (2010). Teaching generalized imitation skills to a preschooler with autism using video modeling. Journal of Positive Behavior Interventions, 12,116-127.

Lamb, J. A. (2011). Whole genome linkage and association analyses. In D. G. Amaral, G. Dawson, \& D.H. Geschwind (Eds), Autism spectrum disorder (pp. 699-689). New York: Oxford University Press.

Landa, R. J., Holman, K. C., \& Garrett-Mayer, E. (2007). Social and communication development in toddlers with early and later diagnosis of autism spectrum disorders. Archives of General Psychiatry, 64, 853-864.

Landry, R., \& Bryson, S. E. (2004). Impaired disengagement of attention in young children with autism. Journal of Child Psychology and Psychiatry, 45(6), 11151122 .

Lord, C. \& Bishop, S. L. (2010). Autism spectrum disorders: Diagnosis, prevalence, and services for children and families. Social Policy Report, 24(2), 1-21.

Lovaas, O. I., Koegel, R. L., \& Schreibman, L. (1979). Stimulus over selectivity in autism: A review of research. Psychological Bulletin, 86(6), 1236-1254.

Maenner, M. J., Shaw, K. A., Baio, J., Washington, A., Patrick, M., DiRienzo, M., Dietz, P. M. (2020). Prevalence of autism spectrum disorder among children aged 8 years-Autism and Developmental Disabilities Monitoring Network, 11 Sites, United States, 2016. MMWR Surveill Summ 2020;69(No. SS-4): 1-12. doi: http://dx.doi.org/10.15585/mmwr.ss6904a1

Mattard-Labrecque, C., Amor, L. B., \& Couture, M. M. (2013). Children with autism and attention difficulties: A pilot study of the association between sensory, motor, and adaptive behaviors. Journal of the Canadian Academy of Child and Adolescent Psychiatry, 22(2), 139.

Mechling, L. (2005). The effect of instructor-created video programs to teach students with disabilities: A literature review. Journal of Special Education Technology, 20, 25-36.

Mechling, L. C., Ayres, K. M., Bryant, K. J., \& Foster, A. L. (2014). Continuous video modeling to assist with completion of multi-step home living tasks by young adults with moderate intellectual disability. Education and Training in Autism and Developmental Disabilities, 49(3), 368.

Mechling, L. C., Ayres, K. M., Purrazzella, K., \& Purrazzella, K. (2014). Continuous video modeling to prompt completion of multi-component tasks by adults with 
moderate intellectual disability. Education and Training in Autism and Developmental Disabilities, 49(1), 3-16.

McCoy, K., \& Hermansen, E. (2007). Video modeling for individuals with autism: A review of model types and effects. Education and Treatment of Children, 30(4), 183-213.

Mosey, A. C. (1986). Occupational therapy. New York, NY: John Wiley \& Sons.

Napolioni, V., Lombardi, F., Sacco, R., Curatolo, P., Manzi, B., Alessandrelli, R., \& Persico, A. M. (2011). Family-based association study of ITGB3 in autism spectrum disorder and its endophenotypes. European Journal of Humanities, 19, 353-359.

Nietupski, J., Clancy, P., \& Christiansen, C. (1984). Acquisition, maintenance and generalization of vending machine purchasing skills by moderately handicapped students. Education and Training of the Mentally Retarded, 19(2), 91-96.

Nietupski, J., Welch, J., \& Wacker, D. (1983). Acquisition, maintenance, and transfer of grocery item purchasing skills by moderately and severely handicapped students. Education and Training of the Mentally Retarded, 18(4), 279-286.

Nikopoulos, C. K. (2007). Use of video modeling to increase generalization of social play by children with autism. The Journal of Speech and Language Pathology-Applied Behavior Analysis, 2(2), 195-212.

Parker, R. I., Vannest, K. J., \& Davis, J. L. (2011). Effect size in single-case research: A review of nine nonoverlap techniques. Behavior Modification, 35(4), 303-322.

Paterson, C. R., \& Arco, L. (2007). Using video modeling for generalizing toy play in children with autism. Behavior Modification, 31, 660-681.

Pierce, K. L., \& Schreibman, L. (1994). Teaching daily living skills to children with autism in unsupervised settings through pictorial self-management. Journal of Applied Behavior Analysis, 27(3), 471-481.

Quill, K. A. (1997). Instructional considerations for young children with autism: The rationale for visually cued instruction. Journal of Autism and Developmental Disorders, 27(6), 697-714.

Quill, K. A. (1995). Introduction. In K. A. Quill (Ed.), Teaching children with autism strategies enhance communication and socialization (pp. 1-32). New York: Delmar. 
Rakap, S. (2015). Effect sizes as a result interpretation aids in single-subject experimental research: Description and application of four nonoverlap methods. British Journal of Special Education, 42(1), 12-33.

Ratajczak, H. V. (2011). Theoretical aspects of autism: Causes, A review. Journal of Immunotoxicology, 8(1), 68-79. doi:10.3109/1547691X.2010.545086

Rayner, C., Denholm, C., \& Sigafoos, J. (2009). Video-based intervention for individuals with autism: Key questions that remain unanswered. Research in Autism Spectrum Disorders, 3(2), 291-303.

Richards, S., Taylor, R., \& Ramasamy, R. (2014). Single subject research: Applications in educational and clinical settings. Boston, MA: Cengage Learning.

Rieth, S. R., Stahmer, A. C., Suhrheinrich, J., \& Schreibman, L. (2015). Examination of the prevalence of stimulus overselectivity in children with ASD. Journal of Applied Behavior Analysis, 48(1), 71-84.

Sancho, K., Sidener, T. M., Reeve, S. A., \& Sidener, D. W. (2010). Two variations of video modeling interventions for teaching play skills to children with autism. Education and Treatment of Children, 33, 421-442.

Scattone, D. (2008). Enhancing the conversation skills of a boy with Asperger's disorder through Social Stories ${ }^{\mathrm{TM}}$ and video modeling. Journal of Autism and Developmental Disorders, 38(2), 395-400.

Schopler, E., Van Bourgondien, M. E., Wellman, G. J., \& Love, S. R. (2010). Childhood autism rating scale (2nd ed.). Torrance, CA: Western Psychological Services.

Schunk, D. H. (2012). Learning theories: An educational perspective (6th ed.). Boston: Pearson.

Scott, J., \& Bennett, K. D. (2012). Applied behavior analysis and learners with Autism Spectrum Disorders. In D. Zager, M. L. Wehmeyer, \& R. L. Simpson (Eds.), Educating students with autism spectrum disorders: Research-based principles and practices (pp. 63-81). New York: Routledge.

Scott, J., Clark, C., \& Brady, M. P. (2000). Students with Autism, characteristics and instructional programming. Belmont, CA: Wadsworth.

Sherer, M., Pierce, K., Paredes, S., Kisacky, K., Ingersoll, B., \& Schreibman, L. (2001). Enhancing conversation skills in children with autism via video technology: Which is better, "Self' or "Other' as a model? Behavior Modification, 25, 140158. 
Shipley-Benamou, R., Lutzker, J. R., \& Taubman, M. (2002). Teaching daily living skills to children with autism through instructional video modeling. Journal of Positive Behavior Interventions, 4, 165-175.

Shukla-Mehta, S., Miller, T., \& Callahan, K. J. (2010). Evaluating the effectiveness of video instruction on social and communication skills training for children with autism spectrum disorders: A review of the literature. Focus on Autism and Other Developmental Disabilities, 25, 23-26.

Sicile-Kira, C. (2004). Autism spectrum disorders: The complete guide to understanding autism, Asperger's syndrome, pervasive developmental disorder, and other ASDs. New York: Berkley Publishing Group.

Sigafoos, J., O’Reilly, M., Cannella, H., Edrisinha, C., de la Cruz, B., Upadhyaya, M.,...Young, D. (2007). Evaluation of a video prompting and fading procedure for teaching dish washing skills to adults with developmental disabilities. Journal of Behavioral Education, 16(2), 93-109.

Sigafoos, J., O’Reilly, M., Cannella, H., Upadhyaya, M., Edrisinha, C., Lancioni, G. E., Young, D. (2005). Computer-presented video prompting for teaching microwave oven use to three adults with developmental disabilities. Journal of Behavioral Education, 14, 189-201.

Simpson, R. L., \& Myles, B. S. (1998). Aggression among children and youth who have Asperger's syndrome: A different population requiring different strategies.

Preventing school failure: Alternative Education for Children and Youth, 42(4), 149-153. doi: 10.1080/10459889809603730

Smith, I., Lowe-Pearce, C., \& Nichols, S. (2006). Assessment of imitation abilities in autism: Conceptual and methodological Issues. In S. Rogers \& J. Willams (Eds.), Imitation and the social mind: Autism and typical development (pp. 377-398). New York: Guilford.

Sterponi, L. \& Shankey, J. (2013). Rethinking echolalia: Repetition as interactional resource in the communication of a child with autism. Journal of Child Language, 41(2), 275-304.

Taber-Doughty, T., Patton, S. E., \& Brennan, S. (2008). Simultaneous and delayed video modeling: An examination of system effectiveness and student preferences. Journal of Special Education Technology, 23(1), 283-311.

Tereshko, L., MacDonald, R., \& Ahearn, W. H. (2010). Strategies for teaching children with autism to imitate response chains using video modeling. Research in Autism Spectrum Disorders, 4, 479-489. 
Test, D. W., Aspel, N. P., \& Everson, J. M. (2006). Transition methods for youth with disabilities. Upper Saddle River: Pearson Prentice Hall.

Tincani, M., Travers, J., \& Boutot, A., (2009). Race, culture, and autism spectrum disorder: Understanding the role of diversity in successful educational interventions. Research and Practice for Persons with Severe Disabilities, 34, 8190.

Travers, B. G, Klinger, M. R., \& Klinger, L. G. (2011). Attention and working memory in ASD. In D. Fein (Ed.), The neuropsychology of autism (pp. 161-184). New York: Oxford University Press.

Van Laarhoven, T., \& Van Laarhoven-Myers, T. (2006). Comparison of three videobased instructional procedures for teaching daily living skills to persons with developmental disabilities. Education and Training in Developmental Disabilities, 41(4), 365-381.

Van Laarhoven, T., Kraus, E., Karpman, K., Nizzi, R., \& Valentino, J. (2010). A comparison of picture and video prompts to teach daily living skills to individuals with Autism. Focus on Autism \& Other Developmental Disabilities, 25(4), 195208.

Volkmar, F. R., \& Wiesner, L. A. (2009). A practical guide to autism: What every parent, family member, and teacher needs to know. Hoboken: John Wiley \& Sons, Inc.

Webster-Stratton C. (1990). Enhancing the effectiveness of self-administered videotape parent training for families with conduct-problem children. Journal of Abnormal Child Psychology, 18, 479-492.

Wolf, M. M. (1978). Social validity: The case for subjective measurement or how applied behavior analysis is finding its heart. Journal of applied behavior analysis, 11(2), 203-214.

Wolff, S. (2004). The history of autism. European Child \& Adolescent Psychiatry, 13(4), 201-208.

Wong, C., Odom, S. L., Hume, K. A., Cox, A. W., Fettig, A., Kucharczyk, S., . . \& Schultz, T. R. (2015). Evidence-based practices for children, youth, and young adults with autism spectrum disorder: a comprehensive review. Journal of Autism and Developmental Disorders, 45, 1951-1966.

Wu, P. F., Cannella-Malone, H. I., Wheaton, J. E., \& Tullis, C. A. (2016). Using video prompting with different fading procedures to teach daily living skills: A preliminary examination. Focus on Autism and Other Developmental Disabilities, 31(2), 129-139. 


\section{Appendices}

\section{Appendix A}

Task Data Collection Form (Baseline-Maintenance)

Participant \#:

Session \#:

Setting:

Start time:

Condition: Baseline

\section{Observer:}

Task:

Date:

End time:

Maintenance:

Directions: Mark plus (+) if the step is completed correctly and independently. Mark minus (-) if the step is not completed correctly and independently.

\begin{tabular}{|c|c|c|c|c|c|c|c|}
\hline Task Analysis Step & $\begin{array}{r}\mathrm{Pa} \\
\mathrm{r} \\
+=\mathrm{c} \\
-=\mathrm{i}\end{array}$ & & & be & $\mathrm{C}$ & $\mathrm{Lc}$ & \\
\hline 1-Put the green paper on the table. & + & - & 1 & 2 & 3 & 4 & 5 \\
\hline 2-Put the yellow paper on the table. & + & . & 1 & 2 & 3 & 4 & 5 \\
\hline 3-Put the blue paper on the table. & + & - & 1 & 2 & 3 & 4 & 5 \\
\hline $\begin{array}{l}\text { 4- Pick up the papers and tap the table } \\
\text { with the papers or straighten the } \\
\text { papers on the table. }\end{array}$ & + & - & 1 & 2 & 3 & 4 & 5 \\
\hline 5-Fold the papers in half. & + & - & 1 & 2 & 3 & 4 & 5 \\
\hline $\begin{array}{l}\text { 6-Pick up the envelope and open the } \\
\text { envelop. }\end{array}$ & + & - & 1 & 2 & 3 & 4 & 5 \\
\hline 7-Put the papers in the envelope. & + & - & 1 & 2 & 3 & 4 & 5 \\
\hline $\begin{array}{l}\text { 8-Put the envelop on the table } \\
\text { with the papers in the envelope. }\end{array}$ & + & - & 1 & 2 & 3 & 4 & 5 \\
\hline $\begin{array}{l}\text { 9-Take the paper covering the seal off } \\
\text { the envelope. }\end{array}$ & + & - & 1 & 2 & 3 & 4 & 5 \\
\hline
\end{tabular}




\begin{tabular}{|l|c|c|c|c|c|c|c|}
\hline $\begin{array}{l}\text { 10- Throw away the small sealing } \\
\text { paper. }\end{array}$ & + & - & 1 & 2 & 3 & 4 & 5 \\
\hline $\begin{array}{l}\text { 11- Close the envelope with the papers } \\
\text { in the envelope. }\end{array}$ & + & - & 1 & 2 & 3 & 4 & 5 \\
\hline $\begin{array}{l}\text { 12- Press the envelope with the papers } \\
\text { in the envelope. }\end{array}$ & + & - & 1 & 2 & 3 & 4 & 5 \\
\hline $\begin{array}{l}\text { 13- Put the envelope in the basket with } \\
\text { the papers in the sealed envelope. }\end{array}$ & + & - & 1 & 2 & 3 & 4 & 5 \\
\hline
\end{tabular}

Number of correct responses:

Number of incorrect responses:

Percentage of correct responses: 


\section{Appendix B}

Task Data Collection Form (Intervention)

\begin{tabular}{|ll|}
\hline Participant \#: & Observer: \\
Session \#: & Task: \\
Setting: & Date: \\
Start time: & End time: \\
Condition: Intervention & \\
\hline
\end{tabular}

Directions: Mark plus (+) if the step is completed correctly and independently. Mark minus (-) if the step is not completed correctly and independently.

\begin{tabular}{|c|c|c|c|c|c|c|c|}
\hline Task Analysis Step & $\begin{array}{r}\text { Par } \\
\text { res } \\
+=\mathrm{c} \\
-=\text { in }\end{array}$ & & & $\mathrm{Im}$ & of & P L & \\
\hline 1-Put the green paper on the table. & + & - & 1 & 2 & 3 & 4 & 5 \\
\hline 2-Put the yellow paper on the table. & + & - & 1 & 2 & 3 & 4 & 5 \\
\hline 3-Put the blue paper on the table. & + & - & 1 & 2 & 3 & 4 & 5 \\
\hline $\begin{array}{l}\text { 4- Pick up the papers and tap the table } \\
\text { with the papers or straighten the } \\
\text { papers on the table. }\end{array}$ & + & - & 1 & 2 & 3 & 4 & 5 \\
\hline 5-Fold the papers in half. & + & - & 1 & 2 & 3 & 4 & 5 \\
\hline $\begin{array}{l}\text { 6-Pick up the envelope and open the } \\
\text { envelop. }\end{array}$ & + & - & 1 & 2 & 3 & 4 & 5 \\
\hline 7-Put the papers in the envelope. & + & - & 1 & 2 & 3 & 4 & 5 \\
\hline $\begin{array}{l}\text { 8-Put the envelop on the table } \\
\text { with the papers in the envelope. }\end{array}$ & + & - & 1 & 2 & 3 & 4 & 5 \\
\hline $\begin{array}{l}\text { 9-Take the paper covering the seal off } \\
\text { the envelope. }\end{array}$ & + & - & 1 & 2 & 3 & 4 & 5 \\
\hline $\begin{array}{l}\text { 10- Throw away the small sealing } \\
\text { paper. }\end{array}$ & + & - & 1 & 2 & 3 & 4 & 5 \\
\hline $\begin{array}{l}\text { 11- Close the envelope with the papers } \\
\text { in the envelope. }\end{array}$ & + & - & 1 & 2 & 3 & 4 & 5 \\
\hline
\end{tabular}




\begin{tabular}{|l|c|c|c|c|c|c|c|}
\hline $\begin{array}{l}\text { 12- Press the envelope with the papers } \\
\text { in the envelope. }\end{array}$ & + & - & 1 & 2 & 3 & 4 & 5 \\
\hline $\begin{array}{l}\text { 13- Put the envelope in the basket with } \\
\text { the papers in the sealed envelope. }\end{array}$ & + & - & 1 & 2 & 3 & 4 & 5 \\
\hline
\end{tabular}

Number of correct responses:

Number of incorrect responses:

Percentage of correct responses: 


\section{Appendix C}

Interobserver Agreement (IOA) Data Form (Baseline and Maintenance)

Participant \#:

Session \#:

Setting:

Start time:

Condition: Baseline
Observer:

Task:

Date:

End time:

Maintenance

\begin{tabular}{|l|l|l|l|}
\hline \multicolumn{1}{|c|}{ Task Analysis Steps } & $\begin{array}{c}\text { Researcher } \\
\text { Score }\end{array}$ & $\begin{array}{c}\text { Second } \\
\text { Observer } \\
\text { Score }\end{array}$ & $\begin{array}{c}\text { Agreement/ } \\
\text { Disagreement }\end{array}$ \\
\hline 1-Put the green paper on the table. & & & \\
\hline 2-Put the yellow paper on the table. & & & \\
\hline 3-Put the blue paper on the table. & & & \\
\hline $\begin{array}{l}\text { 4- Pick up the papers and tap the table } \\
\text { with the papers or straighten the papers } \\
\text { on the table. }\end{array}$ & & & \\
\hline 5-Fold the papers in half. & & & \\
\hline $\begin{array}{l}\text { 6-Pick up the envelope and open the } \\
\text { envelop. }\end{array}$ & & & \\
\hline 7-Put the papers in the envelope. & & & \\
\hline $\begin{array}{l}\text { 8-Put the envelop on the table } \\
\text { with the papers in the envelope. }\end{array}$ & & & \\
\hline $\begin{array}{l}\text { 9-Take the paper covering the seal off } \\
\text { the envelope. }\end{array}$ & & & \\
\hline 10- Throw away the small sealing paper. & & & \\
\hline $\begin{array}{l}\text { 11- Close the envelope with the papers in } \\
\text { the envelope. }\end{array}$ & & & \\
\hline $\begin{array}{l}\text { 12- Press the envelope with the papers in } \\
\text { the envelope. } \\
\text { the papers in the sealed envelope. }\end{array}$ & & & \\
\hline 13- Put the envelope in the basket with & & & \\
\hline
\end{tabular}


Number of agreements:

Number of disagreements: 


\section{Appendix D}

Interobserver Agreement (IOA) Data Form (Intervention)

Participant \#:

Session \#:

Setting:

Start time:

Condition: Intervention
Observer:

Task:

Date:

End time:

\begin{tabular}{|l|l|l|l|}
\hline \multicolumn{1}{|c|}{ Task Analysis Steps } & $\begin{array}{c}\text { Researcher } \\
\text { Score }\end{array}$ & $\begin{array}{c}\text { Second } \\
\text { Observer } \\
\text { Score }\end{array}$ & $\begin{array}{c}\text { Agreement/ } \\
\text { Disagreeme } \\
\text { nt }\end{array}$ \\
\hline 1-Put the green paper on the table. & & & \\
\hline 2-Put the yellow paper on the table. & & & \\
\hline 3-Put the blue paper on the table. & & & \\
\hline $\begin{array}{l}\text { 4- Pick up the papers and tap the table } \\
\text { on the table. }\end{array}$ & & & \\
\hline 5-Fold the papers in half. & & & \\
\hline $\begin{array}{l}\text { 6-Pick up the envelope and open the } \\
\text { envelop. }\end{array}$ & & & \\
\hline 7-Put the papers in the envelope. & & & \\
\hline $\begin{array}{l}\text { 8-Put the envelop on the table } \\
\text { with the papers in the envelope. }\end{array}$ & & & \\
\hline $\begin{array}{l}\text { 9-Take the paper covering the seal off the } \\
\text { envelope. }\end{array}$ & & & \\
\hline $\begin{array}{l}\text { 10- Throw away the small sealing paper. } \\
\text { 11- Close the envelope with the papers in } \\
\text { the envelope. }\end{array}$ & & & \\
\hline $\begin{array}{l}\text { 12- Press the envelope with the papers in } \\
\text { the envelope. }\end{array}$ & & & \\
\hline $\begin{array}{l}\text { 13- Put the envelope in the basket with } \\
\text { the papers in the sealed envelope. }\end{array}$ & & & \\
\hline
\end{tabular}


Number of agreements:

Number of disagreements: 


\section{Appendix E}

Treatment Fidelity Data Collection Form (Baseline and Maintenance)

\begin{tabular}{ll|}
\hline Participant \#: & Observer: \\
Session \#: & Task: \\
Setting: & Date: \\
Start time: & End time: \\
Condition: Baseline & Maintenance \\
\hline
\end{tabular}

Directions: Mark plus (+) for correct implementation of the procedure. Mark minus (-) for incorrect implementation of the procedure. Mark (N/A) if not required or not applicable.

\begin{tabular}{|l|l|l|l|}
\hline \multicolumn{1}{|c|}{ Planned Steps } & \multicolumn{2}{|c|}{ Implemented (+/ / NA) } \\
\hline $\begin{array}{l}\text { 1-The researcher was near the participant } \\
\text { with task materials prepared and placed in } \\
\text { front of the participant. }\end{array}$ & + & - & NA \\
\hline $\begin{array}{l}\text { 2-The researcher provided a verbal } \\
\text { instruction to the participant to start the } \\
\text { task. }\end{array}$ & + & + & NA \\
\hline $\begin{array}{l}\text { 3-The researcher did not provide } \\
\text { instructional prompts to the participant } \\
\text { and CVP was not applied. }\end{array}$ & + & - & NA \\
\hline $\begin{array}{l}\text { 4-If no performance for 30s, the } \\
\text { researcher asked the participant if they } \\
\text { were finished. }\end{array}$ & + & NA \\
\hline $\begin{array}{l}\text { 5-If participant said they were finished } \\
\text { with the task; the researcher ended the } \\
\text { session. }\end{array}$ & + & - & NA \\
\hline $\begin{array}{l}\text { 6-If participant said they were not } \\
\text { finished with the task, the researcher let } \\
\text { them continue. }\end{array}$ & + & - & NA \\
\hline $\begin{array}{l}\text { 7-The researcher thanked the participant } \\
\text { at the end of the session. }\end{array}$ & + & - & NA \\
\hline
\end{tabular}

Number of correct implementations:

Percentage of treatment fidelity: 


\section{Appendix F}

Treatment Fidelity Data Collection Form (Intervention)

\begin{tabular}{ll|}
\hline Participant \#: & Observer: \\
Session \#: & Task: \\
Setting: & Date: \\
Start time: & End time: \\
Condition: Intervention & \\
\hline
\end{tabular}

Directions: Mark plus (+) for correct implementation of the procedure. Mark minus (-) for incorrect implementation of the procedure. Mark (N/A) if not required.

\begin{tabular}{|l|c|c|c|}
\hline \multicolumn{1}{|c|}{ Planned Procedures } & \multicolumn{2}{|c|}{$\begin{array}{c}\text { Implemented } \\
\text { (+/-/NA) }\end{array}$} \\
\hline $\begin{array}{l}\text { 1-The researcher was near the participant with task materials } \\
\text { prepared and iPad placed in front of the participant. }\end{array}$ & + & - & NA \\
\hline $\begin{array}{l}\text { 2-The researcher provided a verbal instruction to the participant } \\
\text { to start the task. }\end{array}$ & + & - & NA \\
\hline $\begin{array}{l}\text { 3-The researcher said, "Watch the video" and then said, "Now } \\
\text { you do it" before each video clip. }\end{array}$ & + & - & NA \\
\hline \begin{tabular}{l} 
4-The researcher played the video for the participant. \\
\hline $\begin{array}{l}\text { 5-The researcher allowed the video clip to repeat up to five } \\
\text { times or until the participant performed the step correct. }\end{array}$
\end{tabular} & + & - & NA \\
\hline $\begin{array}{l}\text { 6-The researcher provided verbal praise to the participant for } \\
\text { correct responses. }\end{array}$ & + & - & NA \\
\hline $\begin{array}{l}\text { 7-When the participant did the step incorrectly at any time } \\
\text { while the video was playing during one of the five loops, the } \\
\text { researcher asked the participant to turn around, completed that } \\
\text { step for him or her, advanced the video to the next step of the } \\
\text { task, and asked the participant to turn around to view the next } \\
\text { video. }\end{array}$ & + & - & NA \\
\hline $\begin{array}{l}\text { 8-After the fifth video loop played, participants were given 5 } \\
\text { seconds to initiate the step and 30 seconds to complete the step. } \\
\text { If the participant performed the step within 5 seconds and } \\
\text { completed the step within 30 seconds, the researcher provided } \\
\text { verbal praise to the participant for the correct response. }\end{array}$ & + & - & NA \\
\hline $\begin{array}{l}\text { 9-After the fifth video loop played, if the participant did not } \\
\text { respond within 5 seconds or did not complete the step within }\end{array}$ & + & - & NA \\
\hline
\end{tabular}




\begin{tabular}{|l|l|l|l|}
\hline $\begin{array}{l}30 \text { seconds or did not complete the step correctly, the } \\
\text { researcher asked the participant to turn around, completed that } \\
\text { step for him or her, advanced the video to the next step of the } \\
\text { task, and asked the participant to turn around to view the next } \\
\text { video. }\end{array}$ & & & \\
\hline $\begin{array}{l}10-\text { At the end of the session, and if the participant scored 11 } \\
\text { out of } 13 \text { steps of the task analysis correctly, the researcher } \\
\text { provided the reinforcer of the participant's choice using the } \\
\text { preference assessment data. }\end{array}$ & + & - & NA \\
\hline
\end{tabular}

Number of correct implementations:

Percentage of treatment fidelity: 


\section{Appendix G}

\section{Participant Social Validity Questionnaire Data Form}

Participant ID:

Instructions: Select the choice that represents your opinion.

\begin{tabular}{|l|c|c|}
\hline \multicolumn{1}{|c|}{ Question } & Yes & Maybe
\end{tabular}




\section{Appendix H}

Teacher Social Validity Questionnaire Data Form

Participant ID:

Instructions: Select the choice that represents your opinion.

\begin{tabular}{|l|l|l|l|l|l|}
\hline \multicolumn{1}{|c|}{ Questions } & $\begin{array}{c}\text { Strongly } \\
\text { Agree }\end{array}$ & Agree & Neither & Disagree & $\begin{array}{c}\text { Strongly } \\
\text { Disagree }\end{array}$ \\
\hline $\begin{array}{l}\text { 1-We worked on a skill that was } \\
\text { important for the participants to } \\
\text { learn? }\end{array}$ & & & & & \\
\hline $\begin{array}{l}\text { 2-The intervention was } \\
\text { acceptable to me given my } \\
\text { classroom demands. }\end{array}$ & & & & & \\
\hline 3-The intervention was effective. & & & & & \\
\hline $\begin{array}{l}\text { 4-I would use CVP to teach DLS } \\
\text { to other students? }\end{array}$ & & & & & \\
\hline $\begin{array}{l}\text { 5-I was satisfied with the } \\
\text { intervention. }\end{array}$ & & & & & \\
\hline
\end{tabular}




\section{Appendix I}

Multiple Stimulus Without Replacement Preference Assessment

Data Collection Form

Participant ID:

Instructions: Score the stimuli according to the when the participant selected them (i.e., $1=$ first item selected through $5=$ last item selected). Total the scores. The stimulus with the lowest number is the first ranked stimulus. The stimulus with the highest number is the fifth ranked stimulus. Record the remaining stimuli accordingly. List the stimuli according to the rankings.

\section{Ranking of Stimuli}

1.

2.

3.

4.

5.

\section{Trials}

\begin{tabular}{|l|c|c|c|c|c|c|}
\hline Stimulus & Attempt & Attempt & Attempt & Attempt & Attempt & Score \\
\hline 1. & 1 & 2 & 3 & 4 & 5 & \\
\hline 2. & & & & & & \\
\hline 3. & & & & & & \\
\hline 4. & & & & & & \\
\hline 5. & & & & & & \\
\hline
\end{tabular}


Adapted from Cannella-Malone, H. I., Sabielny, L. M., Jimenez, E. D., \& Miller, M. M. (2013). Pick one! Conducting preference assessments with students with significant disabilities. Teaching Exceptional Children, 45(6), 16-23. 
ENAS MOHAMMEDNOUR ALTAF

Education and Experience

2020

(Anticipated Summer 2020) Doctor of Education, Exceptional Student Education

Florida International University

Miami, Florida

2013-2014

Doctoral Course Work in Special Education

New Mexico State University

Las Cruces, New Mexico

2013

Master of Science, Special Education

Adelphi University

Garden City, New York

2004

Bachelor of Science, Biology King

Abdulaziz University (KAU)

Jeddah, Saudi Arabia

2015-present

College Instructor

Special Education Department

Umm A1-Qura University

Makkah, Saudi Arabia

2007

Lap Teacher in Private School

Future School

Jeddah, Saudi Arabia

2005

General Education Teacher in Private School

Albayan Model School

Jeddah, Saudi Arabia

Publications

Bennett, K.D., Aljehany, M.S., \& Altaf, E.M. (2017). Systematic review of video-based instruction component and parametric analyses. Journal of Special Education Technology, 32(2), 80-90. 